\title{
REVIEW ARTICLE \\ Glyphosate, pathways to modern diseases II: Celiac sprue and gluten intolerance
}

\author{
Anthony SAMSEL ${ }^{1}$ and Stephanie SENEFF 2
}

1 Independent Scientist and Consultant, Deerfield, NH 03037, USA

${ }^{2}$ Computer Science and Artificial Intelligence Laboratory, MIT, Cambridge, MA, USA

ITX060413R01 • Received:24 September 2013 • Revised: 10 November 2013 • Accepted: 12 November 2013

\begin{abstract}
Celiac disease, and, more generally, gluten intolerance, is a growing problem worldwide, but especially in North America and Europe, where an estimated $5 \%$ of the population now suffers from it. Symptoms include nausea, diarrhea, skin rashes, macrocytic anemia and depression. It is a multifactorial disease associated with numerous nutritional deficiencies as well as reproductive issues and increased risk to thyroid disease, kidney failure and cancer. Here, we propose that glyphosate, the active ingredient in the herbicide, Roundup is the most important causal factor in this epidemic. Fish exposed to glyphosate develop digestive problems that are reminiscent of celiac disease. Celiac disease is associated with imbalances in gut bacteria that can be fully explained by the known effects of glyphosate on gut bacteria. Characteristics of celiac disease point to impairment in many cytochrome P450 enzymes, which are involved with detoxifying environmental toxins, activating vitamin D3, catabolizing vitamin A, and maintaining bile acid production and sulfate supplies to the gut. Glyphosate is known to inhibit cytochrome P450 enzymes. Deficiencies in iron, cobalt, molybdenum, copper and other rare metals associated with celiac disease can be attributed to glyphosate's strong ability to chelate these elements. Deficiencies in tryptophan, tyrosine, methionine and selenomethionine associated with celiac disease match glyphosate's known depletion of these amino acids. Celiac disease patients have an increased risk to non-Hodgkin's lymphoma, which has also been implicated in glyphosate exposure. Reproductive issues associated with celiac disease, such as infertility, miscarriages, and birth defects, can also be explained by glyphosate. Glyphosate residues in wheat and other crops are likely increasing recently due to the growing practice of crop desiccation just prior to the harvest. We argue that the practice of "ripening" sugar cane with glyphosate may explain the recent surge in kidney failure among agricultural workers in Central America. We conclude with a plea to governments to reconsider policies regarding the safety of glyphosate residues in foods.
\end{abstract}

KEY WORDS: celiac disease; gluten; glyphosate; food; cytochrome P450; deficiency

\section{Introduction}

Gluten intolerance is a growing epidemic in the U.S. and, increasingly, worldwide. Celiac sprue is a more specific disorder, characterized by gluten intolerance along with autoantibodies to the protein, transglutaminase, which builds crosslinks in undigested fragments of gliadin, a major constituent of gluten (Green \& Cellier, 2007). The autoantibodies are produced as an immune response to undegraded fragments of proteins in gluten. A remarkable set of symptoms develop over time in association with celiac disease, including weight loss, diarrhea, chronic

\section{Correspondence addres:}

\section{Stephanie Seneff, PhD}

Computer Science and Artificial Intelligence Laboratory,

Massachusetts Institute of Technology,

Rm G-438 MIT Stata Center, 32 Vassar Street, Cambridge, MA 02139, USA

TEL.: +1-617-253-0451 • FAX: +1-617-258-8642

E-MAIL: seneff@csail.mit.edu fatigue, neurological disorders, anemia, nausea, skin rashes, depression, and nutrient deficiencies. Usually, but not always, a strict gluten-free diet can alleviate many of the symptoms. A key associated pathology is an inflammatory response in the upper small intestine, leading to villous atrophy, a flattening of the microvilli which impairs their ability to function in their important role in absorbing nutrients.

Some have suggested that the recent surge in celiac disease is simply due to better diagnostic tools. However, a recent study tested frozen sera obtained between 1948 and 1954 for antibodies to gluten, and compared the results with sera obtained from a matched sample from people living today (Rubio-Topia et al., 2009). They identified a four-fold increase in the incidence of celiac disease in the newer cohort compared to the older one. They also determined that undiagnosed celiac disease is associated with a 4-fold increased risk of death, mostly due to 
increased cancer risk. They concluded that the prevalence of undiagnosed celiac disease has increased dramatically in the United States during the past 50 years.

Transglutaminases play many important roles in the body, as they form covalent crosslinks in complex proteins in connection with blood coagulation, skinbarrier formation, extracellular matrix assembly, and fertilization, endowing the substrate with protection from degradation by proteases (Lorand \& Graham, 2003). They also form crosslinks in undigested fragments of gliadin derived from wheat, and sensitivity to certain of these fragments leads to the development of autoantibodies to tissue transglutaminase (Esposito et al., 2002) that inhibit its activity.

Glyphosate is the active ingredient in the herbicide Roundup. It is a broad-spectrum herbicide, considered to be nearly nontoxic to humans (Williams et al., 2000). However, a recent paper (Samsel \& Seneff, 2013), argued that glyphosate may be a key contributor to the obesity epidemic and the autism epidemic in the United States, as well as to several other diseases and conditions, such as Alzheimer's disease, Parkinson's disease, infertility, depression, and cancer. Glyphosate suppresses 5-enolpyruvylshikimic acid-3-phosphate synthase (EPSP synthase), the rate-limiting step in the synthesis of the aromatic amino acids, tryptophan, tyrosine, and phenylalanine, in the shikimate pathway of bacteria, archaea and plants (de María et al., 1996). In plants, aromatic amino acids collectively represent up to $35 \%$ of the plant dry mass (Franz, 1997). This mode of action is unique to glyphosate among all emergent herbicides. Humans do not possess this pathway, and therefore we depend upon our ingested food and our gut microbes to provide these essential nutrients. Glyphosate, patented as an antimicrobial (Monsanto Technology LLC, 2010), has been shown to disrupt gut bacteria in animals, preferentially killing beneficial forms and causing an overgrowth of pathogens. Two other properties of glyphosate also negatively impact human health - chelation of minerals such as iron and cobalt, and interference with cytochrome P450 (CYP) enzymes, which play many important roles in the body. We will have much more to say about these aspects in later sections of this paper.

A recent study on glyphosate exposure in carnivorous fish revealed remarkable adverse effects throughout the digestive system (Senapati et al., 2009). The activity of protease, lipase, and amylase were all decreased in the esophagus, stomach, and intestine of these fish following exposure to glyphosate. The authors also observed "disruption of mucosal folds and disarray of microvilli structure" in the intestinal wall, along with an exaggerated secretion of mucin throughout the alimentary tract. These features are highly reminiscent of celiac disease. Gluten peptides in wheat are hydrophobic and therefore resistant to degradation by gastric, pancreatic and intestinal proteases (Hershko \& Patz, 2008). Thus, the evidence from this effect on fish suggests that glyphosate may interfere with the breakdown of complex proteins in the human stomach, leaving larger fragments of wheat in the human gut that will then trigger an autoimmune

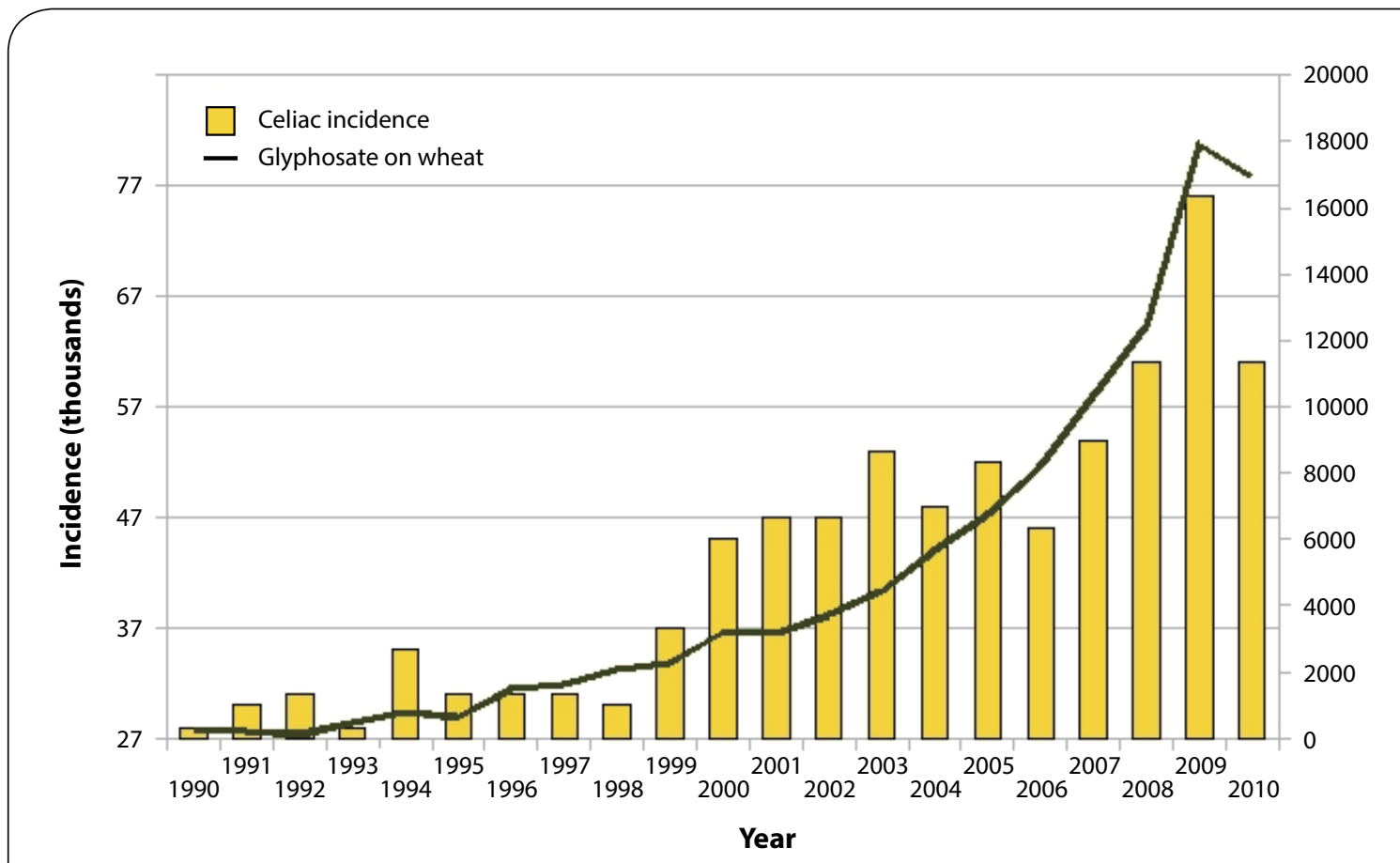

Figure 1. Hospital discharge diagnosis (any) of celiac disease ICD-9 579 and glyphosate applications to wheat ( $\mathrm{R}=0.9759, p \leq 1.862 \mathrm{e}-06$ ). Sources: USDA:NASS; CDC. (Figure courtesy of Nancy Swanson). 
response, leading to the defects in the lining of the small intestine that are characteristic of these fish exposed to glyphosate and of celiac patients. As illustrated in Figure 1, the usage of glyphosate on wheat in the U.S. has risen sharply in the last decade, in step with the sharp rise in the incidence of Celiac disease. We explain the reasons for increased application of glyphosate to wheat in Section 13.

In the remainder of this paper, we will first show that gut dysbiosis, brought on by exposure to glyphosate, plays a crucial role in the development of celiac disease. Many CYP enzymes are impaired in association with celiac disease, and we show that glyphosate's known suppression of CYP enzyme activity in plants and animals plausibly explains this effect in humans. In Section 4, we describe the role of excess retinoic acid in celiac disease, and show how this ties also to reproductive problems. We link this to the known effects of glyphosate on retinoic acid, mediated by its suppression of CYP enzymes. Section 5 addresses cobalamin deficiency, a known pathology associated with celiac disease that leads to macrocytic anemia. We argue that this follows as a direct consequence of glyphosate's ability to chelate cobalt. Section 6 discusses in more depth the role of anemia in celiac disease, a consequence of both cobalamin and iron deficiency. Section 7 discusses molybdenum deficiency and its link to microcephaly, which is associated with celiac disease. Section 8 discusses the link between selenium deficiency and autoimmune thyroid disease. Section 9 discusses kidney disease in connection with celiac disease and glyphosate. Section 10 discusses various nutritional deficiencies associated with celiac disease, and shows how these can directly be explained by glyphosate. Section 11 discusses the link between celiac disease and certain rare cancers that have also been linked to glyphosate. Section 12 goes into an in-depth discussion of how glyphosate might promote autoantibodies to transglutaminase. Following a section which presents compelling evidence that glyphosate residues in wheat, sugar and other crops are likely increasing in recent decades, and a section discussing the increased risk to kidney failure in agricultural workers exposed to excess glyphosate occupationally, we close with a discussion section that summarizes our findings, and a conclusion which implores governments to pay more attention to the damaging consequences of the escalation in chemical warfare on weeds that characterizes current agricultural practices.

\section{Gut bacteria}

In this section, we first discuss the role of pathogens in inducing the breakdown of tight junctions in enterocytes lining the small intestinal wall. We then show that glyphosate is associated with an overgrowth of pathogens along with an inflammatory bowel disease in animal models. A parallel exists with celiac disease where the bacteria that are positively and negatively affected by glyphosate are overgrown or underrepresented respectively in association with celiac disease in humans. We also discuss how the beneficial bacteria that are negatively impacted by glyphosate can protect from celiac disease through their enzymatic activities on gluten, and point to several articles recommending treatment plans based on probiotics.

Pathogens, through their activation of a potent signaling molecule called zonulin, induce a breakdown of the tight junctions in cells lining the gut, leading to "leaky gut" syndrome (Fasano, 2011). Concentrations of zonulin were sharply elevated $(p<0.000001)$ in subjects with celiac disease during the acute phase (Fasano et al., 2000). As many as $30 \%$ of celiac patients continue to experience GI symptoms after adopting a gluten-free diet, despite optimal adherence, a condition that was attributed to bacterial overgrowth in the small intestine (Tursi et al., 2003). Figure 2 shows that there is a correlation between glyphosate application to wheat and the incidence of intestinal infections.

Evidence of disruption of gut bacteria by glyphosate is available for poultry (Shehata et al., 2013), cattle (Krüger et al., 2013), and swine (Carman et al., 2013). Glyphosate disrupts the balance of gut bacteria in poultry (Shehata $e t$ $a l ., 2013)$, increasing the ratio of pathogenic bacteria to other commensal microbes. Salmonella and Clostridium are highly resistant to glyphosate, whereas Enterococcus, Bifidobacteria, and Lactobacillus are especially susceptible. Glyphosate was proposed as a possible factor in the increased risk to Clostridium botulinum infection in cattle in Germany over the past ten to fifteen years (Krüger et al., 2013b). Pigs fed GMO corn and soy developed widespread intestinal inflammation that may have been due in part to glyphosate exposure (Carman et al., 2013).

Celiac disease is associated with reduced levels of Enterococcus, Bifidobacteria and Lactobacillus in the gut and an overgrowth of pathogenic gram negative bacteria (Sanz et al., 2011; Di Cagno et al., 2011; Collado et al., 2007). In (Di Cagno et al., 2011), Lactobacillus, Enterococcus and Bifidobacteria were found to be significantly lower in fecal samples of children with celiac disease compared to controls, while levels of the pathogens, Bacteroides, Staphylococcus, Salmonella, a Shighella were elevated. In (Collado et al., 2007), another study comparing the fecal material of celiac infants to healthy controls, Bacteroides, Clostridium and Staphylococcus were all found to be significantly higher $(p<0.05)$. Sulfate-reducing bacterial counts were also elevated $(p<0.05)$ (Nadal et al., 2007; Collado et al., 2007), an interesting observation which we will return to later in this paper. A significant reduction in Bifidobacteria was also found in (Nadal et al., 2007). An increased excretion of the bacterial metabolites p-Cresol and phenol has also been recognized in association with celiac disease (Tamm, 1984). p-Cresol is produced via anaerobic metabolism of tyrosine by pathogenic bacteria such as Clostridium difficile (D'Ari and Barker, 1985). It is a highly toxic carcinogen, which also causes adverse effects on the central nervous system, the cardiovascular system, lungs, kidney and liver (Kelly et al., 1994).

Probiotic treatments are recommended to aid in digestive healing in celiac disease. The proteolytic activity of 


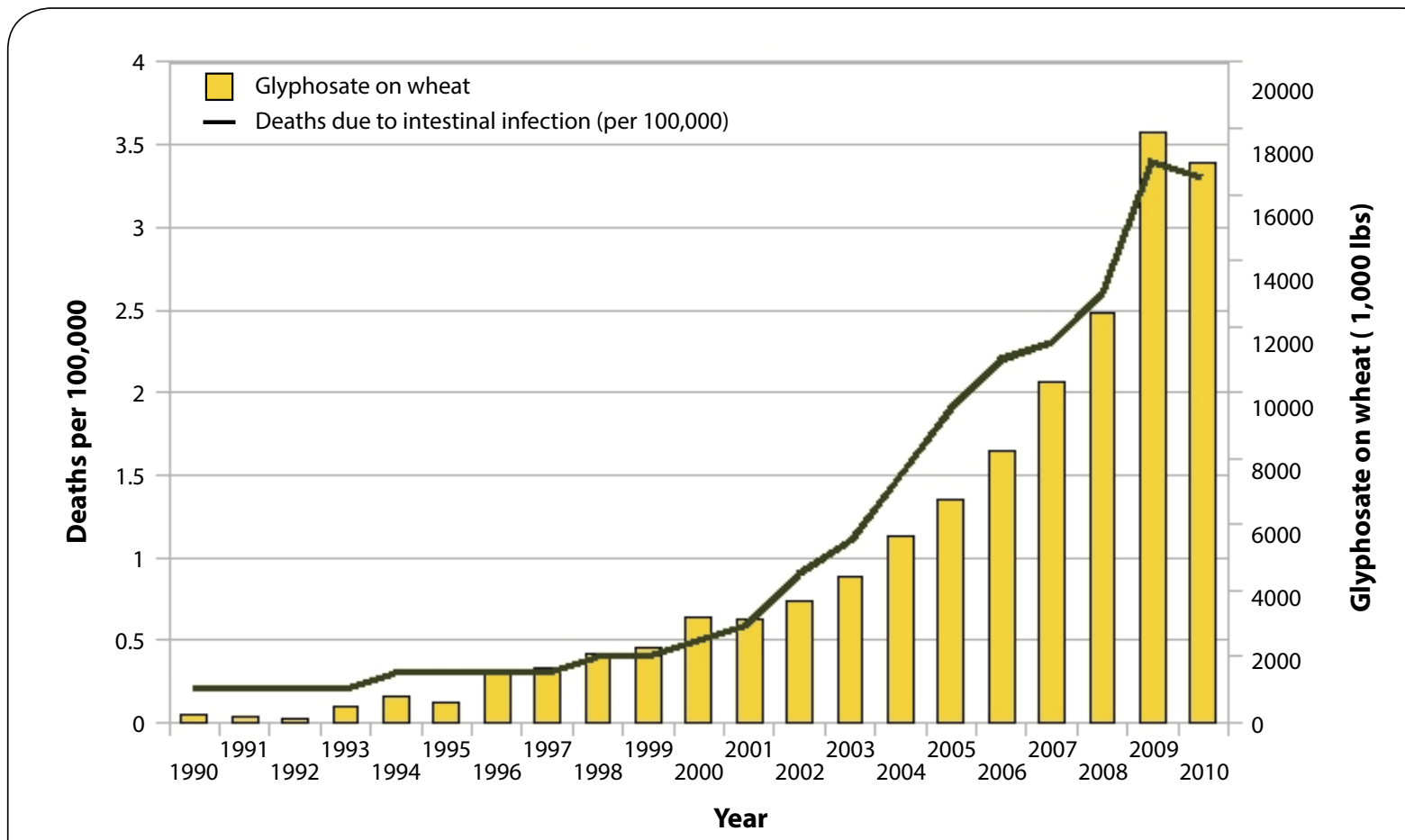

Figure 2. Deaths due to intestinal infections ICD A04, A09; 008, 009 with glyphosate applications to wheat $(R=0.9834, p \leq 3.975 e-09)$. Sources: USDA:NASS; CDC. (Figure courtesy of Nancy Swanson).

Lactobacilli aids the breakdown of wheat into less allergenic forms. Ongoing research aims to produce glutencontaining sourdough breads fermented by Lactobacilli that can then serve as probiotics to help ameliorate the symptoms of celiac disease and allow celiac patients to consume wheat (Gobbetti et al., 2007). Probiotic Lactobacilli produce the enzyme phytase which breaks down phytates that would otherwise deplete important minerals and other cations through chelation (Famularo et al., 2005). Their activities would therefore improve absorption of these micronutrients, a known problem in celiac patients (Cavallaro et al., 2004). Glyphosate itself also chelates rare minerals, a subject we will address in the section on nutritional deficiencies.

Probiotic treatment with Bifidobacteria has been shown to alleviate symptoms associated with celiac disease (Smecuol et al., 2013; Whorwell et al., 2006). Bifidobacteria suppress the pro-inflammatory milieu triggered by the microbiota of celiac patients (Medina et al., 2008). Live cultures of Bifidobacterium lactis would promote healing of the gut if offered as treatment in conjunction with the gluten-free diet, or might even allow the celiac patient to consume modest amounts of gluten without damaging effects (Lindfors et al., 2008). In this in vitro study, it was demonstrated that $\mathrm{B}$. lactis reduced epithelial permeability and improved the integrity of the tight junctions in human colon cells.

In summary, celiac disease is associated with a reduced presence in the gut of commensal bacteria such as Lactobacilli and Bifidobacteria, which are known to be preferentially killed by glyphosate, and with an overabundance of C. difficile, which is known to be promoted by glyphosate exposure. Bifidobacteria and Lactobacilli are both capable of modifying gluten in such a way as to make it less allergenic, a feature that is being exploited in recent efforts to develop gluten-containing foods that may be safe for consumption by celiac patients. Probiotics containing live forms of these bacteria are also being actively marketed today.

\section{CYP Enzyme impairment and sulfate depletion}

As mentioned previously, glyphosate has been shown to suppress CYP enzymes in plants (Lamb et al., 1998) and animals (Hietanen et al., 1983). A study on rats demonstrated that glyphosate decreased the levels of CYP enzymes and monooxygenase activities in the liver and the intestinal activity of aryl hydrocarbon hydroxylase (Hietanen et al., 1983).

CYP enzymes are essential for detoxification of many compounds in the liver (Lindros, 1997). Intraperitoneal exposure of rats to Roundup in acute doses over a short time interval induced irreversible damage to hepatocytes and elevated urinary markers of kidney disease. This was associated with lipid peroxidation and elevated levels of the inflammatory cytokine tumor necrosis factor (TNF- $\alpha$ ) (El-Shenawy, 2009). CYP3A is constitutively expressed in human intestinal villi and plays an important role in 
drug metabolism (Cupp \& Tracy, 1998). Celiac disease is associated with a decrease in the intestinal CYP3A (Lang et al., 1996). This defect is restored by a gluten free diet.

Impaired gallbladder bile acid production (Colombato et al., 1977) and biliary cirrhosis, an inflammatory liver disease characterized by obstruction of the bile duct (Dickey et al., 1997), have been shown to co-occur with celiac disease. CYP enzymes are crucial in the production of bile acids (Lorbek et al., 2012). An obligatory CYP enzyme in bile acid synthesis, CYP27A, has been identified as being identical to the mitochondrial vitamin D3 activating enzyme (Wikvall, 2001). In (Kemppainen et al., 1999), $64 \%$ of men and $71 \%$ of women with celiac disease were found to be vitamin D3 deficient, manifested as low spinal bone mineral density. Celiac disease is associated with impaired gall bladder function and decreased pancreatic secretions (Brown et al., 1987; Benini et al., 2012) along with recurrent pancreatitis (Patel et al., 1999). Abnormalities in bile acid secretion have been found in children suffering from celiac disease (Ejderhamn et al., 1992). Celiac patients exhibit abnormally low synthesis of cholecystokinin (Deprez et al., 2002), but it has also become apparent that the gall bladder is less responsive to stimulation of contraction by cholecystokinin (Brown et al., 1987). A reversible defect of gallbladder emptying and cholecystokinin release has been identified in association with celiac disease (Maton et al., 1985). These pathologies may be related to impaired CYP enzyme activity induced by glyphosate.

While it is clear that CYP enzymes play an important role in bile acid synthesis and in cholesterol homeostasis, the details have not yet been worked out (Lorbek et al., 2012). However, some mouse knockout experiments produce embryonically lethal effects, pointing to the importance of these enzymes to biological systems. Disruption of Cyp7A1, involved in bile acid synthesis in mice, induces elevated serum cholesterol and early death.

A link has been established between celiac disease and non-alcoholic fatty liver, which is likely due to the liver's inability to export cholesterol sulfate through the bile acids due to impaired CYP enzymes (Lorbek et al., 2012). This requires a private store of fats to house the excess cholesterol that cannot be exported in bile. This would also likely lead to insufficient sulfate supplies to the small intestine, and could result in impaired heparan sulfate synthesis in the glycosaminoglycans and subsequent pathologies. Heparan sulfate populating the glycosaminoglycans (GAGs) surrounding enterocytes is essential for the proper functioning of the small intestines. Leakage of both albumin and water in both the vasculature and tissues results when the negative charge is reduced due to insufficient sulfation of the polysaccharide units (Sunergren et al., 1987). Vascular leakage may be a consequence of degradation of sulfated GAGs due to inflammatory agents (Klein et al., 1992). A similar problem may occur in the kidneys leading to albumin loss into urine during nephrosis (Vernier et al., 1983). Intestinal protein loss in inflammatory enteropathy associated with celiac disease may also be due to a deficiency in the sulfated
GAGs (Murch et al., 1993; Murch, 1995). A case study of three infants with congenital absence of enterocyte heparan sulfate demonstrated profound enteric protein loss with secretory diarrhoea and absorption failure, even though their intestines were not inflamed (Murch et al., 1996).

In (Samsel and Seneff, 2013), a hypothesis was developed that glyphosate disrupts the transport of sulfate from the gut to the liver and pancreas, due to its competition as a similarly kosmotropic solute that also increases blood viscosity. (Kosmotropes are ions that induce "structure ordering" and "salting out" of suspended particles in colloids). Insufficient sulfate supply to the liver is a simple explanation for reduced bile acid production. The problem is compounded by impaired CYP enzymatic action and impaired cycling of bile acids through defective enterocytes in the upper small intestine. The catastrophic effect of loss of bile acids to the feces due to impaired reuptake compels the liver to adopt a conservative approach of significantly reduced bile acid synthesis, which, in turn, leads to gall bladder disease.

The protein, Nuclear factor $k$-lightchain-enhancer of activated B cells (NF-kB) controls DNA transcription of hundreds of genes and is a key regulator of the immune response to infection (Tieri et al., 2012). Light chains are polypeptide subunits of immunoglobulins. NF-kB responds to stimulation from bacterial and viral antigens, inflammatory cytokines like TNF- $\alpha$, free radicals, oxidized LDL, DNA damage and UV light. The incidence of acute pancreatitis has been increasing in recent years (Bhatia, 2012), and it often follows billiary disease. A local inflammatory reaction at the site of injury coincides with an increase in the synthesis of hydrogen sulfide $\left(\mathrm{H}_{2} \mathrm{~S}\right)$ gas. $\mathrm{H}_{2} \mathrm{~S}$ regulates the inflammatory response by exciting the extracellular signal regulated (ERK) pathway, leading to production of NF-kB (Bhatia, 2012). We hypothesize that $\mathrm{H}_{2} \mathrm{~S}$, while toxic, is a source of both energy and sulfate for the pancreas, derived from sulfur-containing amino acids such as cysteine and homocysteine. Dehydroepiandrosterone (DHEA) sulfate, but not DHEA, inhibits NF- $\mathrm{kB}$ synthesis, suggesting that sulfate deficiency is a driver of inflammation (Iwasaki et al., 2004).

While $\mathrm{H}_{2} \mathrm{~S}$ is well known as a toxic gas through its inhibition of aerobic respiration, a recent paradigm shift in the research surrounding $\mathrm{H}_{2} \mathrm{~S}$ has been inspired by the realization that it is an important signaling gas in the vasculature, on par with nitric oxide (Li et al., 2011). $\mathrm{H}_{2} \mathrm{~S}$ can serve as an inorganic source of energy to mammalian cells (Módis et al., 2013). 3-mercaptopyruvate sulfurtransferae (3MST) is expressed in the vascular endothelium, and it produces $\mathrm{H}_{2} \mathrm{~S}$ from mercaptopyruvate, an intermediary in the breakdown of cysteine (Kimura, 2011). Endogenously produced $\mathrm{H}_{2} \mathrm{~S}$ derived from 3-mercaptopyruvate stimulates additional mitochondrial $\mathrm{H}_{2} \mathrm{~S}$ production, which then is oxidized to thiosulfate via at least three different pathways (Ingenbleek and Kimura, 2013; Hildebrandt and Grieshaber, 2008; Goubern et al., 2007), producing ATP. The inflammatory agent superoxide can act as substrate for the oxidation of $\mathrm{H}_{2} \mathrm{~S}$ to sulfite and subsequently sulfate 
and the activated form, PAPS (Seneff et al., 2012), but will likely induce oxidative damage in the pancreas, particularly, as we will see in section 7 , if molybdenum deficiency impairs sulfite-to-sulfate synthesis.

Pancreatic beta cells express extraordinarily high levels of heparan sulfate, which is essential for their survival (Ziolkowski et al., 2012), since it protects them from ROS-induced cell death. Because sulfate transport via the hepatic portal vein is likely disrupted by glyphosate, $\mathrm{H}_{2} \mathrm{~S}$, whether derived from sulfur-containing amino acids or supplied via diffusion following its production by sulfurreducing bacteria in the gut, can become an important source of sulfur for subsequent sulfate production locally in the pancreatic cells. Pancreatic elastase is a serine protease that is needed to assist in protein degradation, but an overabundance can lead to autolysis of tissues (Ito et al., 1998). Cholesterol sulfate inhibits pancreatic elastase (Ito et al., 1998), so a deficiency in cholesterol sulfate supply due to impaired sulfate supply to the liver and impaired CYP function should increase the risk of tissue digestion by pancreatic enzymes, contributing to the loss of villi in the upper small intestine observed in celiac disease.

In the early 1990's a newly recognized disease began to appear, characterized by eosinophil infiltration into the esophagus, which manifested as dysphagia in adults and refractory reflux symptoms in children (Lucendo \& Sánchez-Cazalilla, 2012). This disease, termed eosinophilic esophagitis (EOE), is associated with a Th2 immune profile and synthesis of the cytokine IL-13, which has direct cytotoxic effects on epithelial cells. A dose-dependent induction of eosinophilia by intratracheal delivery of IL-13 confirms its association with EOE (Mishra and Rothenberg, 2003). An association has been found between EOE and celiac disease (Leslie et al., 2010). Patients with refractory celiac disease that is not corrected by dietary gluten restriction show an increased production of IL-13 in the gut (Gross et al., 2013). The incidence of EOE has increased at alarming rates in Western countries in the last three decades (Furuta et al., 2007; Liacouras et al., 2011; Prasad et al., 2009).

Glyphosate is highly corrosive to the esophageal epidermal lining, with upper GI tract injury observed in 94\% of patients following glyphosate ingestion (Chang et al., 1999). In (Zouaoui et al., 2013), the most common symptoms in an acute response from glyphosate poisoning were oropharyngeal ulceration, nausea and vomiting. We hypothesize that glyphosate induces EOE via a systemic response as well as through direct contact. The pathogenesis of EOE is related to food sensitivities, but airborne exposure to chemicals in the lungs can also induce it, so it does not require physical contact to the allergen (Blanchard \& Rothenberg, 2008). It is conceivable that glyphosate is responsible for the emergence of EOE.

The cytochrome $\mathrm{P} 450$ reductase (CPR) and cytochrome P450 (CP) enzyme system is essential for inducing nitric oxide release from organic nitrates ( $\mathrm{Li}, 2006)$. The nitrate moiety is reduced while simultaneously oxidizing NADPH to NADP+. This system is invoked in organic nitrate drug treatment for cardiovascular therapy.
The reaction depends on anaerobic, acidic conditions, a feature of venous rather than arterial blood. Since $\mathrm{L}$-arginine is substrate for NO synthesis by endothelial nitric oxide synthase (eNOS) under oxidative conditions (Förstermann and Münze, 2006), it is likely that CPR and CP play an important role mainly in stimulating venous smooth muscle relaxation. Impaired venous relaxation would likely contribute to venous thrombosis, which is a well-established complication of celiac disease (Zenjari et al., 1995; Marteau et al., 1994, Grigg, 1999, Halfdanarson et al., 2007).

In summary, celiac disease is associated with multiple pathologies in the digestive system, including impaired gall bladder function, fatty liver, pancreatitis, and EOE. We have argued here that many of these problems can be traced to impaired CYP function in the liver due to glyphosate exposure, leading to insufficient flow of bile acids through the circular pathway between the liver and the gut. This results in a system-wide depletion in sulfate, which induces inflammation in multiple organs to produce sulfate locally. A potential sulfur source for sulfate synthesis could be hydrogen sulfide gas, provided in part by the local breakdown of sulfur-containing amino acids like cysteine and homocysteine and in part by diffusion of the gas produced from inorganic dietary sources by sulfur-reducing bacteria in the large intestine. Impaired CYP enzyme function may also contribute to venous thrombosis, for which celiac disease is an established risk factor.

\section{Retinoic acid, celiac disease and reproductive issues}

In this section, we first establish that excess retinoic acid (RA) is a risk factor for celiac disease. We then show that excess RA leads to complications in pregnancy and teratogenic effects in offspring. Glyphosate has been shown to exhibit teratogenic effects in line with known consequences of excess RA exposure to the embryo, and we propose that the mechanism for this effect may be glyphosate's known disruption of CYP enzymes (Samsel \& Seneff, 2013), which are involved in RA catabolism. This then links glyphosate to increased risk to celiac disease via its direct effects on RA. And it identifies a possibly important factor in the association of celiac disease with reproductive issues. We also discuss other adverse effects of excess retinoic acid and a possible relationship to impaired sulfate supply to the gut.

In celiac disease, $\mathrm{T}$ cells develop antibody responses against dietary gluten, a protein present in wheat (Jabri \& Sollid, 2009). RA, a metabolite of vitamin A, has been shown to play a critical role in the induction of intestinal regulatory responses (Mora et al., 2008; Coombes et al., 2007; Mucida et al., 2007). The peptide in gluten, A-gliadin p31-43, induces interleukin 15 (IL-15), a key cytokine promoting T-cell activation (Hershko \& Patz, 2008). RA synergizes with high levels of IL-15 to promote JNK phosphorylation (Nanda, 2011; DePaolo et al., 2011), which potentiates cellular apoptosis (Putcha et al., 2003). 
IL-15 is a causative factor driving the differentiation of precursor cells into anti-gluten CD4+ and CD8+ Th1 cells in the intestinal mucosa. Furthermore, in (DePaolo et al., 2011), it was discovered that RA exhibits an unanticipated co-adjuvant property to induce Th1 immunity to antigens during infection of the intestinal mucosa with pathogens. Retinoic acid has also been shown to directly suppress transglutaminase activity, another way in which it would negatively impact celiac disease (Thacher et al., 1985). Thus, it is becoming clear that excess exposure to RA would increase risk to celiac disease, and warnings have been issued regarding potential adverse effects of RA supplements on celiac disease.

It is well established that high RA levels leads to teratogenic effects both in human and experimental models. Brain abnormalities such as microcephaly, impairment of hindbrain development, mandibular and midfacial underdevelopment, and cleft palate are all implicated (Sulik et al., 1988; Clotman et al., 1998). Women with celiac disease are known to have higher rates of infertility, miscarriages, and birth defects in their offspring (Freeman, 2010; Martinelli et al., 2000; Dickey et al., 1996; Collin et al., 1996). Excess RA could be a significant factor in these complications.

A possible mechanism by which glyphosate might induce excess RA is via its interference with the CYP enzymes that metabolize RA. There are at least three known CYPs (CYP26A1, CYP26B1 and CYP26C1) that catabolize RA, and they are active in both the embryo and the adult (Taimi et al., 2004). A 1/5000 dilution of glyphosate was sufficient to induce reproducible malformations characteristic of RA exposure in frog embryos (Paganelli et al., 2010). Pathologies included shortening of the trunk, reduction in the size of the head, abnormally small eyes or the presence of only one eye (cyclopia), and other craniofacial malformations in the tadpole. Glyphosate's toxicity to tadpoles has been well demonstrated, as it killed nearly $100 \%$ of larval amphibians exposed in experimental outdoor pond mesocosms (Relyea, 2005).

According to official records, there has been a recent 4-fold increase in developmental malformations in the province of Chaco, Argentina, where glyphosate is used massively on GMO monocrops of soybeans (Carrasco, 2013). In Paraguay, 52 cases of malformations were reported in the offspring of women exposed during pregnancy to agrochemicals, including anencephaly, microcephaly, facial defects, cleft palate, ear malformations, polydactily, and syndactily (Benítez-Leite et al., 2009). In in vitro studies on human cell lines, DNA strand breaks, plasma membrane damage and apoptosis were observed following exposure to glyphosate-based herbicides (Gasnier et al., 2009). Another factor in teratogenetic effects of glyphosate may be the suppression of the activity of androgen-to-estrogen conversion by aromatase, a CYP enzyme (Gasnier et al., 2009).

Ingested vitamin A, a fat-soluble vitamin, is delivered to the blood via the lymph system in chylomicrons, and excess vitamin A is taken up by the liver as retinoic acid for catabolism by CYP enzymes (Russell, 2000). Any remaining retinoic acid that is not catabolized is exported inside LDL particles, and it lingers much longer as retinyl esters in the vasculature in this form (Krasinski et al., 1990). Excess retinoic acid is more readily stored in this way in LDL particles in the elderly. Vitamin A toxicity can lead to fatty liver and liver fibrosis (Russell, 2000) as well as hypertriglyceridemia (Ellis et al., 1986). Vitamin A has a negative effect on cholesterol sulfate synthesis (Jetten $e t$ al., 1989), which might negatively impact the liver's ability to maintain adequate supplies of cholesterol sulfate for the bile acids, and therefore also interfere with the supply of cholesterol sulfate to the gastrointestinal tract.

In summary, glyphosate's disruption of the CYP enzymes responsible for RA catabolism could lead to an excess bioavailability of RA that could contribute adversely to celiac disease, as well as damaging the liver and leading to teratogenic effects in offspring of exposed individuals.

In addition to higher risk to birth defects, individuals with celiac disease have increased risk to infertility (Meloni et al., 1999; Farthing et al., 1982). Increased incidence of hypogonadism, infertility and impotence was observed in a study of 28 males with celiac disease (Farthing et al., 1982). Marked abnormalities of sperm morphology and motility were noted, and endocrine dysfunction was suggested as a probable cause. In studies conducted on Sertoli cells in prepubertal rat testis, exposure to Roundup induced oxidative stress leading to cell death (de Liz Oliveira Cavalli et al., 2013). Roundup induced the opening of L-type voltage dependent calcium channels as well as ryanodine receptors, initiating ER stress and leading to calcium overload and subsequent necrosis. Glutathione was depleted due to upregulation of several glutathione-metabolizing enzymes. This suggests that Roundup would interfere with spermatogenesis, which would impair male fertility.

\section{Cobalamin deficiency}

Untreated celiac disease patients often have elevated levels of homocysteine, associated with folate and/or cobalamin deficiency (Saibeni et al., 2005; Dickey et al., 2008). Species of Lactobacillus and Bifidobacterium have the capability to biosynthesize folate (Rossi et al., 2011), so their disruption by glyphosate could contribute to folate deficiency. Malabsorption in the proximal small intestine could also lead to iron and folate deficiencies. Cobalamin was originally thought to be relatively spared in celiac disease because its absorption is mostly through the terminal ileum, which is unaffected by celiac disease. However, a recent study found that cobalamin deficiency is prevalent in celiac patients. $41 \%$ of the patients studied were found to be deficient in cobalamin $(<220 \mathrm{ng} / \mathrm{L})$, and $31 \%$ of these cobalamin-deficient patients also had folate deficiency (Dahele \& Ghosh, 2001). Either cobalamin or folate deficiency leads directly to impaired methionine synthesis from homocysteine, because these two vitamins are both required for the reaction to take place. This induces 
hyperhomocysteinemia (Refsum et al., 2001), an established risk factor in association with celiac disease (Hadithi et al., 2009). Long-term cobalamin deficiency also leads to neurodegenerative diseases (Herrmann \& Obeid, 2012).

Because a deficiency in cobalamin can generate a large pool of methyl-tetrahydrofolate that is unable to undergo reactions, cobalamin deficiency will often mimic folate deficiency. Cobalamin requires cobalt, centered within its corrin ring, to function. We depend upon our gut bacteria to produce cobalamin, and impaired cobalt supply would obviously lead to reduced synthesis of this critical molecule. Glyphosate is known to chelate +2 cations such as cobalt. Glyphosate complexes with cobalt as a dimer [Co(glyphosate)2]3 in fifteen different stereoisomeric configurations, and it is facile at switching among the different stereoisomers, an unusual kinetic property compared to most Co(III) systems (Cusiel, 2005).

In fact, studies have revealed that glyphosate inhibits other cytosolic enzymes besides EPSP synthase in plants and microbes that also activate steps in the shikimate pathway (Ganson and Jensen, 1988; Bode et al., 1984). Glyphosate potently inhibits three enzymes in the shikimate pathway in yeast (Bode et al., 1984). It has been confirmed that these other enzymes depend upon cobalt as a catalyst, and glyphosate inhibition works through competitive cobalt binding and interference with cobalt supply (Ganson and Jensen, 1988). It has also been proposed that chelation by glyphosate of both cobalt and magnesium contributes to impaired synthesis of aromatic amino acids in Escherichia coli bacteria (Hoagland and Duke, 1982). Thus, it is plausible that glyphosate similarly impairs cobalamin function in humans by chelating cobalt.

\section{Anemia and iron}

Anemia is one of the most common manifestations of celiac disease outside of the intestinal malabsorption issues (Halfdanarson et al., 2007; Bottaro et al., 1999), and is present in up to half of diagnosed celiac patients. Celiac patients often have both cobalamin and folate deficiency, which can cause anemia, but iron deficiency may be the most important factor (Hershko \& Patz, 2008). Celiac patients often don't respond well to iron treatment.

Glyphosate's chelating action can have profound effects on iron in plants (Eker et al., 2006; Bellaloui et al., 2009). Glyphosate interferes with iron assimilation in both glyphosate-resistant and glyphosate-sensitive soybean crops (Bellaloui et al., 2009). It is therefore conceivable that glyphosate's chelation of iron is responsible for the refractory iron deficiency present in celiac disease.

Erythropoietin (EPO), also called hematopoietin, is a cytokine produced by interstitial fibroblasts in the kidney that regulates red blood cell production. Low EPO levels, leading to a low turnover rate of red blood cells, is a feature of celiac disease (Bergamaschi et al., 2008; Hershko \& Patz, 2008). This can lead to megaloblastic anemia, where red blood cells are large (macrocytic) and reduced in number due to impaired DNA synthesis. A recent hematological study on mice exposed to Roundup at subacute levels for just 15 days revealed an anemic syndrome in both male and female mice, with a significant reduction in the number of erythrocytes and in hemoglobin, reduced hematocrit and increased mean corpuscular volume, indicative of macrocytic anemia (Jasper et al., 2012).

\section{Molybdenum deficiency}

Molybdenum deficiency is rarely considered in diagnoses, as it is only needed in trace amounts. However, molybdenum is essential for at least two very important enzymes: sulfite oxidase and xanthine oxidase. Sulfite oxidase converts sulfite, a highly reactive anion, to sulfate, which is much more stable. Sulfite is often present in foods such as wine and dried fruits as a preservative. Sulfate plays an essential role in the sulfated proteoglycans that populate the extracellular matrices of nearly all cell types (Turnbull et al., 2001; Murch et al., 1993; Murch, 1995). So, impaired sulfite oxidase activity leads to both oxidative damage and impaired sulfate supplies to the tissues, such as the enterocytes in the small intestine. The excess presence of sulfur-reducing bacteria such as Desulfovibrio in the gut in association with celiac disease (Collado et al., 2007; Nadal et al., 2007) could be protective, because these bacteria can reduce dietary sulfite to hydrogen sulfide, a highly diffusable gas that can migrate through tissues to provide a source of sulfur for sulfate regeneration at a distant site, as previously discussed. These distal sites could reoxidize the $\mathrm{H}_{2} \mathrm{~S}$ through an alternative pathway that does not require molybdenum for sulfur oxidation (Ingenbleek and Kimura, 2013).

Xanthine oxidase (XO) produces uric acid from xanthine and hypoxanthine, which are derived from purines. It is activated by iron, which, as we have seen, is often intractably deficient in association with celiac disease. Impaired XO activity would be expected to drive purines towards other degradation pathways. Adenosine deaminase (ADA), a cytoplasmic enzyme that is involved in the catabolism of purine bases, is elevated in celiac disease, and is therefore a useful diagnostic marker (Cakal et al., 2010). In fact, elevation of ADA is correlated with an increase in several inflammatory conditions. Impaired purine synthesis is expected in the context of cobalamin deficiency as well, because methyl melonlyl CoA mutase depends on catalytic action by cobalamin (Allen et al., 1993). Decreased purine synthesis results in impaired DNA synthesis, which then leads to megaloblastic anemia (Boss, 1985), due to slowed renewal of RBC's from multipotent progenitors, a problem that is compounded by suppressed EPO activity (Bergamaschi et al., 2008), a feature of celiac disease.

A remarkable recent case of a three-month old infant suffering from molybdenum deficiency links several aspects of glyphosate toxicity together, although glyphosate exposure was not considered as a possible cause in this case (Boles et al., 1993). This child presented with microcephaly, developmental delay, severe irritability, 
and lactic acidosis. Lactic acidosis is a striking feature of intentional glyphosate poisoning induced by drinking Roundup (Zouaoui et al., 2013; Beswick \& Millo, 2011), and it suggests impaired oxidative respiration, as is seen in E. coli exposed to glyphosate (Lu et al., 2013). In vitro studies of glyphosate in the formulation Roundup have demonstrated an ability to disrupt oxidative respiration by inducing mitochondrial swelling and inhibiting mitochondrial complexes II and III (Peixoto, 2005). This would explain a massive build-up of lactic acid following ingestion of Roundup, due to a switch to anaerobic metabolism. Glyphosate has also been shown to uncouple mitochondrial phosphorylation in plants (Haderly et al., 1977; Ali \& Fletcher, 1977).

As has been stated previously, microcephaly is a feature of excess RA, which could be induced by glyphosate due to its inhibitory action on CYP enzymes. In the case study on molybdenum deficiency (Boles et al., 1993), urinary sulfite levels were high, indicative of defective sulfite oxidase activity. Serum hypouricemia was also present, indicative of impaired XO activity. So, the induction of excess RA, depletion of molybdenum, and lactic acidosis by glyphosate provide a plausible environmental factor in this case.

One final aspect of molybdenum deficiency involves nitrate metabolism. As a source of nitric oxide, inorganic nitrite regulates tissue responses to ischemia. While nitrate reductase activity has been known to be a capability of microbes for many years, it has only recently been realized that mammals also possess a functioning nitrate reductase capability, utilizing a molybdenum-dependent enzyme to produce nitrite from nitrate (Jansson et al., 2008). Molybdenum deficiency would impair this capability, likely contributing to the higher risk to venous thrombosis observed in celiac disease (Zenjari et al., 1995; Marteau et al., 1994, Grigg, 1999). This could also explain the excess nitrates in the urine observed in association with celiac disease (Högberg et al., 2011).

\section{Selenium and thyroid disorders}

Autoimmune thyroid disease is associated with celiac disease (Collin et al., 2002; Valentino et al., 2002). In (Valentino et al., 2002), up to $43 \%$ of patients with Hashimoto's thyroiditis showed signs of mucosal T-cell activation typical of celiac disease. Selenium, whose deficiency is associated with celiac disease (Hinks et al., 1984), plays a significant role in thyroid hormone synthesis, secretion and metabolism, and selenium deficiency is therefore a significant factor in thyroid diseases (Sher, 2000; Chanoine et al., 2001; Khrle, 2013).

Selenium is required for the biosynthesis of the "twenty first amino acid," selenocysteine. Twenty five specific selenoproteins are derived from this amino acid. Selenium deficiency can lead to an impairment in immune function and spermatogenesis in addition to thyroid function (Papp et al., 2007). One very important selenoprotein is glutathione peroxidase, which protects cell membranes and cellular components against oxidative damage by both hydrogen peroxide and peroxynitrite $\left(\mathrm{ONOO}^{-}\right)$ (Prabhakar et al., 2006).

Wheat can be a good source of selenoproteins. However, the content of selenium in wheat can range from sufficient to very low, depending upon soil physical conditions. Soil compaction, which results from modern practices of "no till" agriculture (Huggins \& Reganold, 2008), can lead to both reduced selenium content and a significant increase in arsenic content in the wheat (Zhao et al., 2007). Since glyphosate has been shown to deplete sulfur in plants (Saes Zobiole et al., 2010), and selenium is in the same column of the periodic table as sulfur, it is likely that glyphosate also disrupts selenium uptake in plants. A gluten-free diet will guarantee, however, that no selenium is available from wheat, inducing further depletion of selenoproteins, and therefore increasing the risk to immune system, thyroid and infertility problems in treated celiac patients.

The gut bacterium Lactobacillus, which is negatively impacted by glyphosate (Shehata et al., 2013) and depleted in association with celiac disease (Di Cagno et al., 2011), is able to fix inorganic selenium into more bioavailable organic forms like selenocysteine and selenomethionine (Pessione, 2012). Selenocysteine is present in the catalytic center of enzymes that protect the thyroid from free radical damage (Triggiani et al., 2009). Free radical damage would lead to apoptosis and an autoimmune response (Tsatsoulis, 2002). Glyphosate's disruption of these bacteria would lead to a depletion in the supply of selenomethionine and selenocysteine. Methionine depletion by glyphosate (Nafziger et al., 1984) would further compound this problem.

Thus, there are a variety of ways in which glyphosate would be expected to interfere with the supply of selenoproteins to the body, including its effects on Lactobacillus, its depletion of methionine, the no-till farming methods that are possible because weeds are killed chemically, and the likely interference with plant uptake of inorganic selenium. This aligns well with the observed higher risk of thyroid problems in association with celiac disease, in addition to infertility problems and immune issues, which are discussed elsewhere in this paper. Further support for an association between glyphosate and thyroid disease comes from plots over time of the usage of glyphosate in the U.S. on corn and soy time-aligned with plots of the incidence rate of thyroid cancer in the U.S., as shown in Figure 3.

\section{Indole and kidney disease}

The prevalence of kidney disease and resulting dialysis is increasing worldwide, and kidney disease is often associated with increased levels of celiac disease autoantibodies. Kidney disease and thyroid dysfunction are intimately connected (Iglesias \& Díez, 2009). A population-based study in Sweden involving nearly 30,000 people with diagnosed celiac disease determined that there was nearly a three-fold increased risk for kidney failure in this population group (Welander et al., 2012). 


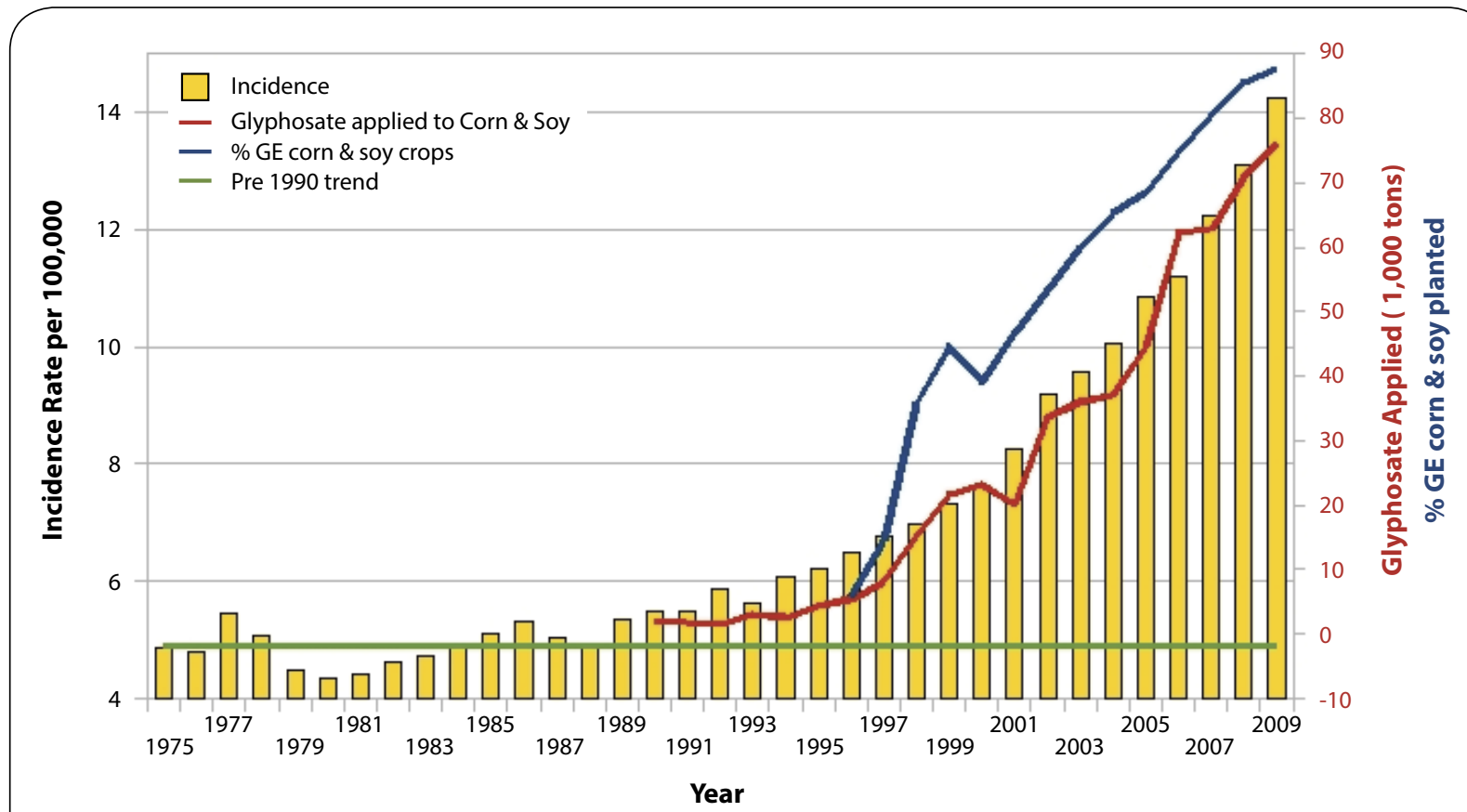

Figure 3. Thyroid cancer incidence rate plotted against glyphosate applied to U.S. corn \& soy crops (R=0.988, $p \leq 7.612 \mathrm{e}-09)$ along with $\% \mathrm{GE}$ corn \& soy crops ( $\mathrm{R}=0.9377, p \leq 2.152 \mathrm{e}-05)$. Sources: USDA:NASS; SEER. (Figure courtesy of Nancy Swanson).

Inflammation plays a crucial role in kidney disease progression (Tonelli et al., 2005; Bash et al., 2009; Rodriguez-Iturbe et al., 2010). Chronic kidney disease develops as a consequence of assaults on the kidney from inflammatory agents, brought on by the induction of proinflammatory cytokines and chemokines in the kidney. The toxic phenol p-Cresol sulfate, as well as indoxyl sulfate, a molecule that is chemically similar to p-Cresol, have been shown to induce activation of many of these cytokines and chemokines (Sun et al., 2012). p-Cresol and indoxyl sulfate both decrease endothelial proliferation and interfere with wound repair (Dou et al., 2004). $\mathrm{p}$-Cresol is produced by the pathogenic bacterium $\mathrm{C}$. difficile, and indoxyl sulfate, derived from indole through sulfation in the liver (Banoglu \& King, 2002), accumulates at high levels in association with chronic kidney disease (Niwa, 2010).

The aromatic amino acid tryptophan contains an indole ring, and therefore disruption of tryptophan synthesis might be expected to generate indole as a byproduct. Indeed, glyphosate has been shown to induce a significant increase in the production of indole-3-acetic acid in yellow nutsedge plants (Caal et al., 1987). Indole is produced by coliform microorganisms such as E. coli under anaerobic conditions. Glyphosate induces a switch in E. coli from aerobic to anaerobic metabolism due to impaired mitochondrial ATP synthesis (Lu et al., 2013; Samsel \& Seneff, 2013), which would likely result in excess production of indole. Besides, E. coli, many other pathogenic bacteria can produce indole, including Bacillus, Shigella, Enterococcus, and V. cholerae (Lee \& Lee, 2010). At least 85 different species of both Gram-positive and
Gram-negative bacteria produce indole, and its breakdown by certain bacterial species depends on CYP enyzmes (Lee \& Lee, 2010). Feeding indole to rats deprived of sulfur metabolites leads to macrocytic anemia (Roe, 1971). Indole is an important biological signaling molecule among microbes (Lee \& Lee, 2010). Indole acetic acid inhibits the growth of cobalamin-dependent microorganisms, which then causes macrocytic (pernicious) anemia in the host due to cobalamin deficiency (Drexler, 1958).

Experiments on exposure of mouse fetuses to indole3 -acetic acid have shown that it dramatically induces microcephaly in developing fetuses exposed at critical times in development (Furukawa et al., 2007). A case study found celiac disease associated with microcephaly and developmental delay in a 15-month-old girl (Bostwick et al., 2001; Lapunzina, 2002). A gluten-free diet restored head growth. The authors suggested that poor head growth might precede other manifestations of celiac disease in infants. A study on plants demonstrated a concentration gradient of indole-3-acetic acid in the plant embryo, similar to the gradient in retinoic acid that controls fetal development in mammals (Uggla et al., 1996). This alternative may be another way in which glyphosate would promote microcephaly.

Thus, solely through its effect on indole production and indole catabolism in gut bacteria, chronic glyphosate exposure would be expected to lead to cobalamin deficiency, pernicious anemia, microcephaly in a fetus during pregnancy, and kidney failure. p-Cresol supply by overgrown pathogens like C. difficile would likely contribute in a similar way as indole, due to its similar biochemical and biophysical properties. 


\section{Nutritional deficiencies}

The damaged villi associated with celiac disease are impaired in their ability to absorb a number of important nutrients, including vitamins B6, B12 (cobalamin) and folate, as well as iron, calcium and vitamins $\mathrm{D}$ and $\mathrm{K}$ (Hallert et al., 2002). Thus, long-term celiac disease leads to major deficiencies in these micronutrients. Cobalamin deficiency has been well addressed previously. We have also already mentioned the chelation of trace minerals by phytates and by glyphosate. However, other factors may be at play as well, as discussed here.

Glyphosate disrupts the synthesis of tryptophan and tyrosine in plants and in gut bacteria, due to its interference with the shikimate pathway (Lu et al., 2013; María et al., 1996), which is its main source of toxicity to plants. Glyphosate also depletes methionine in plants and microbes. A study on serum tryptophan levels in children with celiac disease revealed that untreated children had significantly lower ratios of tryptophan to large neutral amino acids in the blood, and treated children also had lower levels, but the imbalance was less severe (Hernanz \& Polanco, 1991). The authors suggested a metabolic disturbance in tryptophan synthesis rather than impaired absorption, as other similar amino acids were not deficient in the serum. It was proposed that this could lead to decreased synthesis of the monoamine neurotransmitter, serotonin, in the brain associated with behavior disorders in children with celiac disease, such as depression (Koyama \& Melzter, 1986). Deficiencies in tyrosine and methionine were also noted (Hernanz \& Polanco, 1991). "Functional dyspepsia" is an increasing and mainly intractable problem in the Western world, which is estimated to affect $15 \%$ of the U.S. population (Saad \& Chey, 2006). Dyspepsia, a clinical symptom of celiac disease, is likely mediated by excess serotonin synthesis following ingested tryptophan-containing foods (Manocha et al., 2012).

Serotonin (5-hydroxytryptamine or 5-HT) is produced by enterochromaffin (EC) cells in the gut and is an important signaling molecule for the enteric mucosa (Kim et al., 2001). EC cells are the most numerous neuroendocrine cell type in the intestinal lumen, and they regulate gut secretion, motility, pain and nausea by activating primary afferent pathways in the nervous system (Chin et al., 2012). Serotonin plays an important role in activating the immune response and inflammation in the gut, and also induces nausea and diarrhea when it is overexpressed. Anaerobic bacteria in the colon convert sugars into shortchain fatty acids, which can stimulate 5-HT release from EC cells (Fukumoto et al., 2003; Grider \& Piland, 2007). This is likely an important source of fats to the body in the case of a low-fat diet induced by impaired fatty acid metabolism due to insufficient bile acids.

The number of 5-HT expressing EC cells in the small intestine is increased in association with celiac disease, along with crypt hyperplasia (Wheeler \& Challacombe, 1984; Challacombe et al., 1977), and, as a consequence, serotonin uptake from dietary sources of tryptophan is greatly increased in celiac patients (Erspamer, 1986). Postprandial dyspepsia is associated in celiac disease with increased release of 5-HT, and this may account for the digestive symptoms experienced by celiac patients (Coleman et al., 2006). An explanation for these observations is that a chronic tryptophan insufficiency due to the impaired ability of gut bacteria to produce tryptophan induces aggressive uptake whenever dietary tryptophan is available.

Glyphosate forms strong complexes with transition metals, through its carboxylic, phosphonic, and amino moieties, each of which can coordinate to metal ions, and it can also therefore form complexes involving two or three atoms of the targeted transition metal (Madsen et al., 1978; Motekaitis \& Martell, 1985; Undabeytia et al., 2002). This means that it is a metal chelator par excellence. One can expect, therefore, deficiencies in multiple transition (trace) metals, such as iron, copper, cobalt, molybdenum, zinc and magnesium in the presence of glyphosate. Glyphosate has been shown to reduce levels of iron, magnesium, manganese and calcium in non-GMO soybean plants (Cakmak et al., 2009). We have already discussed iron, selenium, cobalt and molybdenum deficiencies in association with celiac disease.

Zinc deficiency seems to be a factor in celiac disease, as a recent study of 30 children with celiac disease demonstrated a significantly reduced serum level of zinc (0.64 vs $0.94 \mu \mathrm{g} / \mathrm{mL}$ in controls) (Singhal et al., 2008). Copper deficiency is a feature of celiac disease (Halfdanarson et al., 2009), and copper is one of the transition metals that glyphosate binds to and chelates (Madsen, 1978; Undabeytia, 2002). Confirmed magnesium deficiency in celiac disease has been shown to be due to significant loss through the feces (Goldman et al., 1962). This would be expected through binding to phytates and/or glyphosate. A study of 23 patients with gluten-sensitive enteropathy to assess magnesium status revealed that only one had serum magnesium levels below the normal range, whereas magnesium levels in erythrocytes and lymphocytes was markedly below normal, and this was associated with evidence of osteoporosis due to malabsorption (Rude and Olerich, 1996). Daily treatment with $\mathrm{MgCl}_{2}$ or $\mathrm{Mg}$ lactate led to a significant increase in bone mineral density, and was correlated with a rise in $\mathrm{RBC} \mathrm{Mg}^{2+}$.

A recent study investigated the status of $25(\mathrm{OH})$ vitamin D3 in adults and children with celiac disease (Lerner et al., 2012). It was determined that vitamin D3 deficiency was much more prevalent in the adults than in the children, suggesting a deterioration in vitamin D3 serum levels with age. This could be explained by a chronic accumulation of glyphosate, leading to increasingly impaired vitamin D3 activation in the liver. The liver converts $1,25(\mathrm{OH})$ vitamin D3 to the active form, 25(OH) vitamin D3, using CYP27A (Ponchon et al., 1969; Sakaki et al., 2005), which might be disrupted by glyphosate exposure, given its known interference with CYP function in mice (Hietanen et al., 1983). On a broader level, this might also explain the recent epidemic in the U.S. in vitamin D3 deficiency (Holick, 2005).

Another issue to consider is whether the food being consumed by celiac patients is itself depleted in nutrients. 
This is likely the case for the transgenic Roundup-Ready crops that increasingly supply the processed food industry. A recent study on the effects of glyphosate on RoundupReady soy revealed a significant effect on growth, as well as an interference with the uptake of both macronutrients and micronutrients (Saes Zobiole et al., 2010). Transgenic soybeans exposed to glyphosate are often affected by a "yellow flashing" or yellowing of the upper leaves, and an increased sensitivity to water stress. An inverse linear relationship was observed between glyphosate dosage and levels of the macronutrients, sodium, calcium, sulfur, phosphorus, potassium, magnesium, and nitrogen, as well as the micronutrients, iron, zinc, manganese, copper, cobalt, molybdenum, and boron. Glyphosate's ability to form insoluble metal complexes likely mediates these depletions (Glass, 1984). Glyphosate also interferes with photosynthesis, as reflected in several measures of photosynthesis rate (Saes et al., 2010) and reductions in chlorophyll (Ali \& Fletcher, 1977; Kitchen et al., 1981). This could be due to depletion of zinc and manganese, since chloroplasts require these micronutrients to function well (Homann, 1967; Thompson \& Weier, 1962).

\section{Cancer}

Chronic inflammation, such as occurs in celiac disease, is a major source of oxidative stress, and is estimated to account for $1 / 3$ of all cancer cases worldwide (Ames et al., 1993; Coussens \& Werb, 2002). Oxidative stress leads to DNA damage and increased risk to genetic mutation. Several population-based studies have confirmed that patients with celiac disease suffer from increased mortality, mainly due to malignancy (Nielsen et al., 1985; Logan et al., 1989; Pricolo et al., 1998; Cottone et al., 1999; Corrao et al., 2001; Green et al., 2003). These include increased risk to non-Hodgkin's lymphoma, adenocarcinoma of the small intestine, and squamous cell carcinomas of the esophagus, mouth, and pharynx, as well as melanoma. The non-Hodgkin's lymphoma was not restricted to gastrointestinal sites, and the increased risk remained following a gluten-free diet (Green et al., 2003).

Celiac disease is associated with a lifelong risk of any malignancy between 8.1 and $13.3 \%$, with the risk for non-Hodgkin's lymphoma alone being 4.3 to $9.6 \%$ (Matheus-Vliezen et al., 1994; Egan et al., 1995). This risk is 19-fold higher than the risk in the general population. Selenium deficiency in association with celiac disease may be a significant factor in the increased cancer risk. Selenium deficiency is associated with increased risk to several cancers, and selenium supplements are beneficial in reducing the incidence of liver cancer and decreasing mortality in colorectal, lung and prostate cancer (Nelson et al., 1999; Björnstedt et al., 2010).

Children with celiac disease, whether or not they are on a gluten-free diet, exhibit elevated urinary biomarkers of DNA damage (Zaflarska-Popawska et al., 2010). Human colon carcinoma cells exposed to peptides extracted from wheat responded with a sharp increase in the GSSG/GSH ratio (ratio of oxidized to reduced glutathione), a wellestablished indicator of oxidative stress (Rivabene, 1999). The authors did not provide information as to whether the wheat plants were exposed to glyphosate, but they did suggest that this effect could explain the increased risk to intestinal cancer associated with celiac. Intriguingly, studies on pea plants have shown that glyphosate induces a sharp increase in the GSSG/GSH ratio in plants (Miteva et al., 2003), which suggests that glyphosate contamination could explain the results observed in (Rivabene, 1999).

Interestingly, it was noted in 1996 that the incidence of both non-Hodgkin's lymphoma and melanoma had been rising sharply worldwide in recent decades, and so it was decided to investigate whether there might be a link between the two cancers associated with sunlight exposure. Surprisingly, the authors found an inverse relationship between non-Hodgkin's lymphoma and UV exposure. More recently, such UV protection has been reaffirmed in a review of epidemiologic studies on the subject (Negri, 2010). This suggests that vitamin D3 is protective, so vitamin D3 deficiency due to impaired CYP function in the liver could be contributory to increased risk in celiac disease.

The incidence of non-Hodgkins lymphoma has increased rapidly in most Western countries over the last few decades. Statistics from the American Cancer Society show an $80 \%$ increase since the early 1970 's, when glyphosate was first introduced on the market.

While there have been only a few studies of lymphoma and glyphosate, nearly all have indicated a potential relationship (Vigfusson \& Vyse, 1980; Pavkov \& Turnier, 1986; Hardell \& Eriksson, 1999; McDuffie et al., 2001; De Roos et al., 2003). A dose-response relationship for non-Hodgkin's lymphoma was demonstrated in a crossCanada study of occupational exposure to glyphosate in men (McDuffie et al., 2001), and a larger study in the U.S. noted a similar result (De Roos et al., 2003). A population-based study in Sweden showed an increased risk to non-Hodgkins lymphoma upon prior exposure to herbicides and fungicides but not insecticides (Hardell \& Eriksson, 1999). Glyphosate exposure resulted in an odds ratio of 2.3, although the number of samples was small, and the authors suggested that further study is necessary. A study on mice showed increases in carcinoma, leukemia and lymphoma (Pavkov \& Turnier, 1986) and an in vitro mutagenic test on human lymphocytes revealed increased sister-chromatid exchanges (Vigfusson \& Vyse, 1980) upon exposure to glyphosate.

\section{Proposed transglutaminase- glyphosate interactions}

Establishing the mechanism by which glyphosate might promote autoantibodies to transglutaminase is a challenging task, not because this possibility seems unlikely but rather because multiple disruptions are plausible. In this section, we present evidence from the research literature that supports various hypotheses for the interaction 
of glyphosate with the transglutaminase enzymatic pathways. The definitive studies that clarify which of these hypotheses is correct have yet to be conducted.

Celiac disease is thought to be primarily caused by ingestion of wheat gluten proteins, particularly gliadin, due to a high concentration of proline- and glutaminerich sequences, which imparts resistance to degradation by proteases. Transglutaminase autoimmunity arises when specific epitopes of wheat gliadin activate sensitized T-cells which then stimulate B-cell synthesis of IgA or IgM autoantibodies to transglutaminase. Transglutaminase bound to gliadin can induce false recognition by a T-cell.

Transglutaminase acts on gluten in wheat to form crosslinks between glutamine residues and lysine residues, producing ammonia as a by-product. Ammonia is known to induce greater sensitivity to glyphosate in plants, and it is common practice to apply ammonium sulfate simultaneously with glyphosate for this reason (Nalewaja \& Matysiak, 1993). This enhanced effect is due to ammonium binding to glyphosate at three sites - one on the carbonyl group and two on the phosphonyl group, which displaces cations such as calcium and endows glyphosate with enhanced reactivity.

Transglutaminase sometimes only achieves half of its intended reaction product, by converting a glutamine residue to glutamate, and leaving lysine intact, thus not producing the desired crosslink. It has been established that gluten fragments containing "deamidated glutamine" residues instead of the crosslinks are much more highly allergenic than those that contain the crosslinks (Dørum et al., 2010; Qiao et al., 2005). These have been referred to as "celiac disease T-Cell epitopes." T-cells of celiac patients preferentially recognize epitopes that are augmented with negatively charged deamidated glutamine residues - the product of the reaction when the lysine linkage does not occur. Thus, if there is a mechanism by which glyphosate interferes with crosslink formation, this would explain its ability to enhance gluten sensitivity.

A clue can be found from the research literature on glyphosate sensitivity in plants, where it has been determined that the substitution of a lysine residue in a critical locale in EPSP synthase greatly increases sensitivity to glyphosate (Selvapandiyan et al., 1995). Lysine's NH3+ group is highly reactive with negatively charged ions, and this makes it a common constituent of DNA binding proteins due to its ability to bind to phosphates in the DNA backbone. Glyphosate contains a phosphonyl group that binds easily to ammonia and behaves as a phosphate mimetic. It also contains a carboxyl group that substitutes well for the carboxyl group of glutamate, the intended reaction partner.

Thus, it seems possible that glyphosate would be drawn to the ammonia released when the glutamine residue is deamidated by transglutaminase, and then the ammonium glyphosate would react with the lysine residue, releasing the ammonia and resulting in the binding of glyphosate to the lysine residue. This would yield a gluten fragment bound to glyphosate that is likely highly allergenic. An analogous EPSP synthase-EPSP-glyphosate ternary complex has been identified in numerous studies on the physiology of glyphosate in plants (Sammons et al., 1995).

Research in the food industry has concerned producing breads that, while not gluten free, may contain forms of gluten to which celiac patients are less sensitive. Such research has revealed that enzymatic modification to promote methionine binding to glutamine reduces IgA immunoreactivity (Cabrera-Chávez et al., 2010). Whether methionine binding to glutamine residues in wheat takes place in vivo is not known, but it is established that glyphosate depletes methionine by 50 to 65 percent in plants, as well as the aromatic amino acids (Nafziger $e t$ al., 1984; Haderlie et al., 1977). As we have already discussed, glyphosate interferes with cobalt bioavailability for cobalamin synthesis, and cobalamin is an essential catalyst for the conversion of cysteine to methionine.

Transglutaminase also cross-links proteins in the extracellular matrix, and therefore is important for wound healing, tissue remodeling, and stabilization of the extracellular matrix. Thus, autoimmunity to transglutaminase leads to destabilization of the microvilli lining the small intestines. Transglutaminase has 18 free cysteine residues which are targets for S-nitrosylation. A cysteine residue is also involved in the catalytic active site. A unique $\mathrm{Ca}^{2+}$ dependent mechanism regulates nitrosylation by $\mathrm{NO}$, mediated by CysNO (S-nitrosocysteine). It was shown experimentally that up to 15 cysteines of transglutaminase were nitrosylated by CysNO in the presence of $\mathrm{Ca}^{2+}$, and this inhibited its enzymatic activity (Lai et al., 2001).

Thus, another plausible mechanism by which glyphosate might enhance the development of autoantibodies to transglutaminase is by nitrosylating its cysteines, acting similarly to CysNO. A precedent for this idea is set with research proposing nitrosylation as the means by which glyphosate interferes with the heme active site in CYP enzymes (Lamb et al., 1998). It is conceivable that cysteine nitrosylation by glyphosate at the active site inactivates the molecule, in which case glyphosate is itself acting as an "antibody."

\section{Evidence of glyphosate exposure in humans and animals}

The US EPA has accepted Monsanto's claim that glyphosate is essentially harmless to humans. Due to this position, there have been virtually no studies undertaken in the US to assess glyphosate levels in human blood or urine. However, a recent study involving multiple countries in Europe provides disturbing confirmation that glyphosate residues are prevalent in the Western diet (Hoppe, 2013). This study involved exclusively city dwellers, who are unlikely to be exposed to glyphosate except through food sources. Despite Europe's more aggressive campaign against GMO foods than that in the Americas, $44 \%$ of the urine samples contained quantifiable amounts of glyphosate. Diet seems to be the main source of exposure. One can predict that, if a study were undertaken in the U.S., the percentage of the affected population would be much larger. 
A recent study conducted on dairy cows in Denmark shows conclusively that the cows' health is being adversely affected by glyphosate (Krüger et al., 2013a). All of the cows had detectable levels of glyphosate in their urine, and it was estimated that from 0.1 to $0.3 \mathrm{mg}$ of glyphosate was excreted daily from each cow. More importantly, all of the cows had serum levels of cobalt and manganese that were far below the minimum reference level for nutrient sufficiency. Half of the cows had high serum urea, and there was a positive linear relationship between serum urea and glyphosate excretion. High serum urea is indicative of nephrotoxicity. Blood serum levels of enzymes indicative of cytotoxicity such as creatine kinase (CK) and alkaline phosphatase (ALP) were also elevated. CK is indicative of rhabdomyolysis or kidney failure. High levels of ALP indicate liver damage, and it is often used to detect blocked bile ducts (Kaplan et al., 1983).

Thus, the low cobalt levels and the indicators of liver, kidney, and gall bladder stress are all consistent with our previous discussion. The results of this study were also consistent with results of a study on rats exposed experimentally to glyphosate (Beuret et al., 2005) in which Roundup was shown to be even more toxic than its active ingredient, glyphosate.

Glyphosate-metal complexes serve to reduce glyphosate's toxicity in the soil to plants, but they also protect glyphosate from attack by microorganisms that could decompose it (Cusiel, 2005). The degree of reactivity of the complex depends on which metals glyphosate binds to, which in turn depends upon the particular soil conditions (Nomura \& Hilton, 1977). Glyphosate usually degrades relatively quickly (Vencill, 2002); however, a half-life of up to 22 years has also been reported in conditions where $\mathrm{pH}$ is low and organic matter contents are high (Nomura \& Hilton, 1977). Therefore, glyphosate may survive much longer in certain soils than has been claimed by the industry, and could be taken up by crops planted subsequent to glyphosate application to kill weeds.

A disturbing trend of crop desiccation by glyphosate pre-harvest (O'Keeffe, 1980; O'Keeffe, 1981; Stride et al., 1985; Darwent et al., 1994; Orson \& Davies, 2007) may be a key factor in the increased incidence of celiac disease. According to Monsanto, glyphosate was used on some $13 \%$ of the wheat area pre-harvest in the UK in 2004. However, by 2006 and 2007, some $94 \%$ of UK growers used glyphosate on at least $40 \%$ of cereal and $80 \%$ of oilseed crops for weed control or harvest management (Monsanto International Sàrl, 2010).

An increasing number of farmers now consider the benefits of desiccating their wheat and sugar cane crops with glyphosate shortly before the harvest (Monsanto International Sàrl, 2010). The advantage is improved harvesting efficiency because the quantity of materials other than grain or cane is reduced by $17 \%$, due to a shutdown of growth following glyphosate treatment. Treated sugar cane crops produce drier stalks which can be baled more easily. There is a shorter delay before the next season's crop can be planted, because the herbicide was applied pre-harvest rather than post-harvest. Several pests can be controlled due to the fact that glyphosate is a broad-spectrum herbicide. These include Black grass, Brome grasses, and Rye grasses, and the suggestion is that this would minimize the risk of these weeds developing resistance to other herbicides.

A complete list of the latest EPA residue levels for glyphosate as of September 18, 2013 are shown in Table 1. Tolerances are established on all crops for both human and animal consumption resulting from the application of glyphosate.

As glyphosate usage continues unabated, glyphosate resistance among weeds is becoming a growing problem (Waltz, 2010), necessitating a strategy that either involves an increase in the amount of glyphosate that is applied or a supplementation with other herbicides such as glufosinate, dicampa, 2-4D, or atrazine. Agrochemical companies are now actively developing crops with resistance to multiple herbicides (Culpepper, 2000), a disturbing trend, especially since glyphosate's disruption of CYP enzymes leads to an impaired ability to break down many other environmental chemicals in the liver.

\section{Kidney disease in agricultural workers}

Chronic kidney disease is a globally increasing problem (Ramirez-Rubio et al., 2013), and glyphosate may be playing a role in this epidemic. A plot showing recent trends in hospitalization for acute kidney injury aligned with glyphosate usage rates on corn and soy shows strong correlation, as illustrated in Figure 4, and a similar correlation is seen for deaths due to end-stage renal disease in Figure 5. Recently, it has been noted that young men in Central America are succumbing in increasing numbers to chronic kidney disease (Trabanino et al., 2002; Cerdas, 2005; Torres et al., 2010; Peraza et al., 2012; RamirezRubio et al., 2013; Sanoff et al., 2010). The problem appears to be especially acute among agricultural workers, mainly in sugar cane fields (Cerdas, 2005; Torres et al., 2010; Peraza et al., 2012). Since we have shown in Section 8 how glyphosate can produce toxic effects on the kidneys through its disruption of gut bacteria, it is fruitful to consider whether glyphosate could be playing a role in the fate of Central American workers in the sugar cane fields.

In attempting to explain this phenomenon, physicians and pharmacists have proposed that it may be due to dehydration caused by over-exertion in high temperature conditions, combined with an acute reaction to commonly administered non-steroidal anti-inflammatory drugs (NSAIDs) to treat pain and/ or antibiotics to treat infection (Ramirez-Rubio et al., 2013). NSAIDs require CYP enzymes in the liver for detoxification (Agúndez et al., 2009), so impaired CYP function by glyphosate would lead to a far more toxic effect of excessive NSAID administration. Kidney disease among agricultural workers tends to be associated with chronic glomerulonephritis and interstial nephritis, which was proposed in (Soderland et al., 2010) to be 
Table 1. Complete list of glyphosate tolerances for residues in food crops in the U.S. as of September 18, 2013, as reported in: EPA: Title 40: Protection of Environment.

\begin{tabular}{|c|c|c|c|c|c|}
\hline Commodity & PPM & Commodity & PPM & Commodity & PPM \\
\hline Acerola & 0.2 & Governor's plum & 0.2 & Quinoa. grain & 5.0 \\
\hline Alfalfa, seed & 0.5 & Gow kee, leaves & 0.2 & Rambutan & 0.2 \\
\hline Almond, hulls & 25 & \multirow{2}{*}{$\begin{array}{l}\text { Grain, cereal, forage, fodder and straw, } \\
\text { group } 16, \text { except field corn, forage and } \\
\text { field corn, stover }\end{array}$} & \multirow{2}{*}{100} & Rice, grain & 0.1 \\
\hline Aloe vera & 0.5 & & & Rice, wild, grain & 0.1 \\
\hline Ambarella & 0.2 & \multirow{2}{*}{$\begin{array}{l}\text { Grain, cereal, group } 15 \text { except field corn, } \\
\text { popcorn, rice, sweet corn, and wild rice }\end{array}$} & \multirow{2}{*}{30} & Rose apple & 0.2 \\
\hline Animal feed, nongrass, group 18 & 400 & & & S apod ilia & 0.2 \\
\hline Artichoke, globe & 0.2 & Grass, forage, fodder and hay, group 17 & 300 & \multirow[b]{2}{*}{ Sapote, mamey } & \multirow[b]{2}{*}{0.2} \\
\hline Asparagus & 0.5 & \multirow{2}{*}{ Herbs subgroup $19 \mathrm{~A}$} & 0.2 & & \\
\hline Atemoya & 0.2 & & 7.0 & Sapote, white & 0.2 \\
\hline Avocado & 0.2 & $\begin{array}{l}\text { Hop, dried cones } \\
\text { llama }\end{array}$ & 0.2 & Shellfish & 3.0 \\
\hline Bamboo, shoots & 0.2 & Imbe & 0.2 & Soursop & 0.2 \\
\hline Barley, bran & 0.2 & Imbu & 0.2 & Spanish lime & 0.2 \\
\hline Beet, sugar, dried pulp & 25 & Jaboticaba & 0.2 & Spearmint, tops & 200 \\
\hline Beet, sugar, roots & 10 & Jackfruit & 0.2 & Spice subgroup 19B & 7.0 \\
\hline Beet, sugar, tops & 10 & Kava, roots & 0.2 & Star apple & 0.2 \\
\hline Berry and small fruit, group 13-07 & 0.20 & Kenaf, forage & 200 & Starfruit & 0.2 \\
\hline Betelnut & 1.0 & Leucaena, forage & 200 & Stevia, dried leaves & 1.0 \\
\hline Biriba & 0.2 & Longan & 0.2 & Sugar apple & 0.2 \\
\hline Blimbe & 0.2 & Lychee & 0.2 & Sugarcane, cane & 2.0 \\
\hline Breadfruit & 0.2 & Mamey apple & 0.2 & Sugarcane, molasses & 30 \\
\hline Cacao bean, bean & 0.2 & Mango & 0.2 & Surinam cherry & 0.2 \\
\hline Cactus, fruit & 0.5 & Mangosteen & 0.2 & Sweet potato & 3.0 \\
\hline Cactus, pads & 0.5 & Marmalade box & 0.2 & Tamarind & 0.2 \\
\hline Canistel & 0.2 & Mioga, flower & 0.2 & Tea. dried & 1.0 \\
\hline Canola. seed & 20 & Noni & 0.20 & Tea, instant & 7.0 \\
\hline Carrot & 5.0 & Nut, pine & 1.0 & Teff, forage & 100 \\
\hline Chaya & 1.0 & Nut, tree, group 14 & 1.0 & TefF, grain & 5.0 \\
\hline Cherimoya & 0.2 & Oilseeds, group 20, except canola & 40 & Teff, hay & 100 \\
\hline Citrus, dried pulp & 1.0 & Okra & 0.5 & $\mathrm{Ti}$, leaves & 0.2 \\
\hline Coconut & 0.1 & Olive & 0.2 & Ti, roots & 0.2 \\
\hline Coffee, bean, green & 1.0 & Oregano, Mexican, leaves & 2,0 & Ugli fruit & 0.5 \\
\hline Corn, pop, grain & 0.1 & Palm heart leaves & 0.2 & Vegetable, bulb, group 3-07 & 0.20 \\
\hline $\begin{array}{l}\text { Corn, sweet, kernel plus cob with husk } \\
\text { removed }\end{array}$ & 3.5 & Palm heart, leaves & 0.1 & Vegetable, cucurbit, group 9 & 0.5 \\
\hline Cotton, gin byproducts & 210 & Papaya & 0.2 & $\begin{array}{l}\text { Vegetable, foliage of legume, subgroup } \\
7 A \text {, except soybean }\end{array}$ & 0.2 \\
\hline Custard apple & 0.2 & Papaya, mountain & 0.2 & Vegetable, fruiting, group 8-10 (except & 0.10 \\
\hline Dried fruit & 0.2 & Passionfruit & 0.2 & & \\
\hline Dokudami & 2.0 & Pawpaw & 0.2 & Vegetable, leafy, brassica. group 5 & 0.2 \\
\hline Durian & 0.2 & Pea, dry & 8.0 & Vegetable, leafy, except brassica, group 4 & 0.2 \\
\hline Epazote & 1.3 & Peanut & 0.1 & Vegetable, leaves of root and tuber, & \\
\hline Feijoa & 0.2 & Peanut, hay & 0.5 & group 2, except sugar beet tops & 0.2 \\
\hline Fig & 0.2 & Pepper leaf, fresh leaves & 0.2 & $\begin{array}{l}\text { Vegetable, legume, group } 6 \text { except soy- } \\
\text { bean and dry pea }\end{array}$ & 5.0 \\
\hline Fish & 0.25 & Peppermint, tops & 200 & Vegetables, root and tuber, group 1, & \\
\hline Fruit, citrus, group 10-10 & 0.50 & Perilla, tops & 1.8 & except carrot, sweet potato, and sugar & 0.20 \\
\hline Fruit, pome, group 11-10 & 0.20 & Persimmon & 0.2 & & \\
\hline Fruit, stone, group 12 & 0.2 & Pineapple & 0.1 & Wasabi. roots & 0.2 \\
\hline Galangal, roots & 0.2 & Pistachio & 1.0 & Water spinach, tops & 0.2 \\
\hline Ginger, white, flower & 0.2 & Pomegranate & 0.2 & Watercress, upland & 0.2 \\
\hline Gourd, buffalo, seed & 0.1 & Pulasan & 0.2 & Wax jambu & 0.2 \\
\hline
\end{tabular}



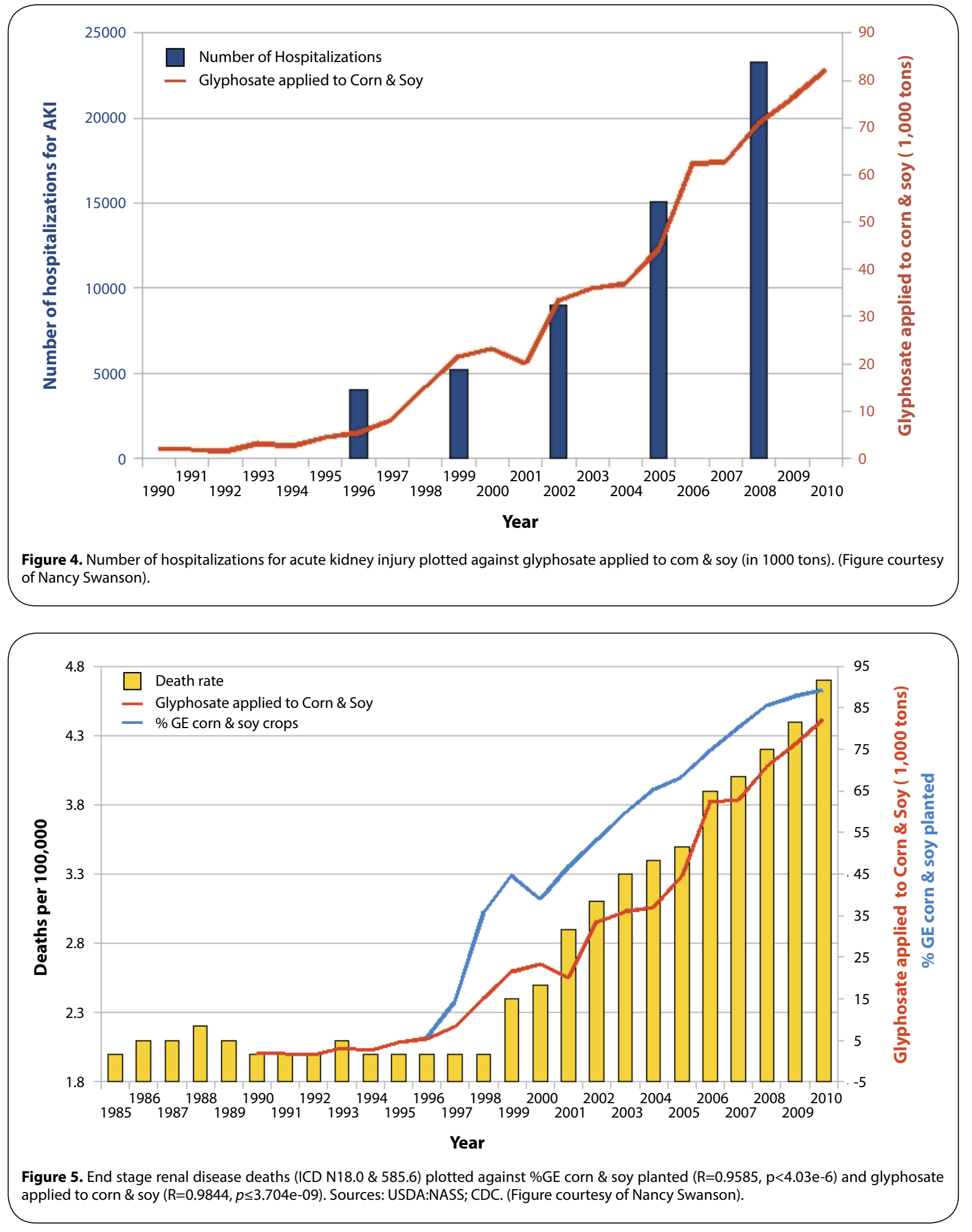

due to environmental toxins such as heavy metals or toxic chemicals. Glomerulonephritis is also found in association with celiac disease (Katz et al., 1979; Peters et al., 2003). A Swedish study showed a five-fold increase in nephritis risk in celiac patients (Peters et al., 2003).
A strong hint comes from epidemiological studies conducted in Costa Rica (Cerdas, 2005). The demographic features of those with chronic renal failure revealed a remarkably specific pattern of young men, between 20 and 40 years old, with chronic interstitial nephritis. All 
of them were sugar-cane workers. These authors wrote: "A specific study of their work environment is needed to determine what in their daily activities puts them at increased risk for chronic renal failure."

Agriculture is an important part of the economy of the state of Louisiana in the United States, and sugar cane is a significant agricultural product. Chemical methods to ripen sugar cane are commonly used, because they can substantially increase the sucrose content of the harvest (Richard \& Dalley, 2009). Glyphosate, in particular, has been the primary ripener used in Louisiana since 1980 (Orgeron, 2012). As of 2001, Louisiana had the highest rate of kidney failure in the U.S. (State-Specific Trends in Chronic Kidney Failure - United States, 1990-2001). Louisiana's death rate per 100,000 from nephritis/kidney disease is 26.34 as compared to a U.S. rate of 14.55 (Network Coordinating Council, 2013). The number of patients on dialysis has risen sharply in the last few years.

By 2005 , it is estimated that $62 \%$ of the total harvested hectares of sugar cane in Louisiana were ripened with glyphosate (Legendre et al., 2005). A paper published in 1990 showed that glyphosate applied as a ripener on three different sugar cane varieties grown in Costa Rica produced up to a $15 \%$ increase in the sucrose content of the harvested sugar cane (Subiros, 1990). Glyphosate applied before the harvest is the only sugarcane ripener currently registered for use in the U.S.

A disturbing recent trend is the repeated application of glyphosate over the course of the season with the hope of further increasing yields (Richard \& Dalley, 2009). Responses to the standard application rate $(0.188 \mathrm{lb} / \mathrm{acre})$ of glyphosate have been inconsistent, and so farmers are increasing both the amount and the frequency of application. In (Richard \& Dalley, 2009), growers are encouraged not to apply glyphosate beyond mid-October, as results are counterproductive, and not to use higher rates in an attempt to improve yield. But it is doubtful that these recommendations are being followed. It is likely, although we have not been able to confirm this, that glyphosate usage has expanded in scope on the sugar cane fields in Central America since 2000, when the expiration of Monsanto's patent drove prices down, and that the practices of multiple applications of glyphosate in the U.S. are also being followed in Central America. Several other ripening agents exist, such as Ethephon, Trinexapacethyl, and Sulfometuron-methyl, but glyphosate is likely growing in popularity recently due to its more favorable pricing and perceived non-toxicity. Larger amounts are needed for effective ripening in regions that are hot and rainy, which matches the climate of Costa Rica and Nicaragua.

\section{Discussion}

In this paper, we have developed an argument that the alarming rise in the incidence of celiac disease in the United States and elsewhere in recent years is due to an increased burden of herbicides, particularly glyphosate exposure in the diet. We suggest that a principal factor is the use of glyphosate to desiccate wheat and other crops prior to the harvest, resulting in crop residue and increased exposure. Strong evidence for a link between glyphosate and celiac disease comes from a study on predatory fish, which showed remarkable effects in the gut that parallel the features of celiac disease (Shenapati et al., 2009).

More generally, inflammatory bowel disease has been linked to several environmental factors, including a higher socioeconomic status, urban as opposed to rural dwelling, and a "Westernized" cultural context (Shapira et al., 2010). Disease incidence is highest in North America and Europe, and is higher in northern latitudes than in southern latitudes within these regions, suggesting a beneficial role for sunlight. According to the most recent statistics from the U.S. Environmental Protection Agency (EPA) (Grube et al., 2011), the U.S. currently represents 25\% of the total world market on herbicide usage. Glyphosate has been the most popular herbicide in the U.S. since 2001, whereas it was the 17th most popular herbicide in 1987 (Kiely et al., 2004). Since 2001, glyphosate usage has grown considerably, due to increased dosing of glyphosateresistant weeds and in conjunction with the widespread adoption of "Roundup-Ready" genetically modified crops. Glyphosate is probably now the most popular herbicide in Europe as well (Kimmel et al., 2013). Glyphosate has become the number one herbicide worldwide, due to its perceived lack of toxicity and its lower price after having become generic in 2000 (Duke \& Powles, 2008).

A recent estimate suggests that one in twenty people in North America and Western Europe suffer from celiac disease (Koning, 2005; Fasano et al., 2003). Outdoor occupational status is protective (Sonnenberg et al., 1991). First generation immigrants into Europe or North America are generally less susceptible, although second generation non-Caucasian immigrants statistically become even more susceptible than native Caucasians (Shapira et al., 2010). This may in part stem from the increased need for sunlight exposure given darker skin pigmentation.

Table 2 summarizes our findings relating glyphosate to celiac disease. All of the known biological effects of glyphosate - cytochrome P450 inhibition, disruption of synthesis of aromatic amino acids, chelation of transition metals, and antibacterial action - contribute to the pathology of celiac disease.

Celiac disease is associated with deficiencies in several essential micronutrients such as vitamin D3, cobalamin, iron, molybdenum, selenium and the amino acids, methionine and tryptophan, all of which can be explained by glyphosate. Glyphosate depletes multiple minerals in both genetically modified soybeans (Saes et al., 2010) and conventional soybeans (Cakmak et al., 2009), which would translate into nutritional deficiencies in foods derived from these crops. This, together with further chelation in the gut by any direct glyphosate exposure, could explain deficiencies in cobalt, molybdenum and iron. Glyphosate's effect on CYP enzymes should lead to inadequate vitamin D3 activation in the liver (Hietanen et al., 1983; Ponchon et al., 1969). Cobalamin depends 
Table 2. Illustration of the myriad ways in which glyphosate can be linked to celiac disease or its associated pathologies. (a) Disruption of gut bacteria

\begin{tabular}{lll}
\hline Glyphosate Effect & Dysfunction & Consequences \\
\hline reduced Bifidobacteria & impaired gluten breakdown & transglutaminase antibodies \\
\hline reduced Lactobacillus & $\begin{array}{l}\text { impaired phytase breakdown } \\
\text { reduced selenoproteins }\end{array}$ & $\begin{array}{l}\text { metal chelation } \\
\text { autoimmune thyroid disease }\end{array}$ \\
\hline anaerobic E. coli & indole toxicity & kidney failure \\
\hline C. diff overgrowth & p-Cresol toxicity & kidney failure \\
\hline Desulfovibrio overgrowth & hydrogen sulfide gas & inflammation
\end{tabular}

(b) Transition metal chelation

\begin{tabular}{|c|c|c|}
\hline Glyphosate Effect & Dysfunction & Consequences \\
\hline cobalt deficiency & $\begin{array}{l}\text { cobalamin deficiency } \\
\text { reduced methionine } \\
\text { elevated homocysteine }\end{array}$ & $\begin{array}{l}\text { neurodegenerative diseases } \\
\text { impaired protein synthesis } \\
\text { heart disease }\end{array}$ \\
\hline molybdenum deficiency & $\begin{array}{l}\text { inhibited sulfite oxidase } \\
\text { inhibited xanthine oxidase }\end{array}$ & $\begin{array}{l}\text { impaired sulfate supply } \\
\text { DNA damage/cancer } \\
\text { teratogenesis } \\
\text { megaloblastic anemia }\end{array}$ \\
\hline iron deficiency & & anemia \\
\hline
\end{tabular}

(c) CYP enzyme inhibition

Glyphosate Impairment

vitamin D3 inactivation

retinoic acid catabolism

bile acid synthesis

xenobiotic detoxification

nitrate reductase

(d) Shikimate pathway suppression

Glyphosate Effect

Dysfunction

Dysfunction

Consequences

impaired calcium metabolism

suppressed transglutaminase

impaired fat metabolism

impaired sulfate supply

increased toxin sensitivity

impaired indole breakdown

venous constriction osteoporosis; cancer risk

teratogenesis

gall bladder disease

pancreatitis

liver disease

macrocytic anemia

kidney failure

venous thrombosis on cobalt, and cobalt-dependent enzymes in plants and microbes have been shown to be inhibited by glyphosate (Bode et al., 1984; Ganson and Jensen, 1988). Glyphosate has been shown to severely impair methionine and tryptophan synthesis in plants (Nafziger et al., 1984), which would reduce the bioavailability of these nutrients in derived foods.

There are multiple intriguing connections between celiac disease and microcephaly, all of which can be linked to glyphosate. Celiac disease is found in association with microcephaly in infants (Bostwick et al., 2001; Lapunzina, 2002), and teratogenic effects are also observed in children born to celiac mothers (Dickey et al., 1996; Martinelli et al., 2000). Microcephaly in an infant where confirmed molybdenum deficiency was present (Boles et al., 1993) suggests that molybdenum deficiency could be causal. However, elevated RA also induces microcephaly, as does indole-3-acetic acid, which has been dramatically linked to microcephaly in mice (Furukawa et al., 2007). Elevated $\mathrm{RA}$ is predicted as a response to glyphosate due to its expected inhibition of CYP enzymes which catabolize RA in the liver (Lamb et al., 1998; Hietanen et al., 1983). Molybdenum deficiency is expected due to glyphosate's ability to chelate cationic minerals. Glyphosate has been shown to induce indole-3-acetic acid synthesis in plants (Caal et al., 1987), and it induces a shift to anaerobic metabolism in E. coli (Lu et al., 2013), which is associated with indole synthesis.

Celiac disease is associated with impaired serotonin metabolism and signaling in the gut, and this feature leads us to propose a novel role for serotonin in transporting sulfate to the tissues. It is a curious and little known fact that glucose and galactose, but not fructose or mannose, stimulate 5 -HT synthesis by EC cells in the intestinal 
lumen (Kim et al., 2001), suggesting a role for EC cells as "glucose sensors." Glucose and galactose are the two sugars that make up the heparan sulfate chains of the syndecans and glypicans that attach to the membranebound proteins in most cells, serving as the innermost constituency of the extracellular matrix (Bernfield et al., 1999). In (Seneff et al., 2012), it was proposed that part of the post-prandial glucose that is taken up by the tissues is temporarily stored in the extracellular matrix as heparan sulfate, and that a deficiency in sulfate supply impairs this process, which impedes glucose uptake in cells. These heparan sulfate units have a high turnover rate, as they are typically broken down within three hours of their initial placement (Turnbull et al., 2001). This provides the cells with a convenient temporary buffer for glucose and galactose that can allow them to more efficiently remove these sugars from the serum. Insufficient sulfate supplies would impair this process and lead to insulin resistance.

As is the case for other monoamine neurotransmitters as well as most sterols, 5-HT is normally transported in the serum in a sulfated form. The sulfate moiety must be removed for the molecule to activate it. Therefore, 5 -HT, as well as these other monoamine neurotransmitters and sterols, can be viewed as a sulfate "escort" in the plasma. In (Samsel \& Seneff, 2013), it was argued that such carbonring-containing molecules are necessary for safe sulfate transport, especially in the face of co-present kosmotropes like glyphosate, in order to protect the blood from excess viscosity during transport. Support for the concept that glyphosate gels the blood comes from the observation that disseminated coagulation is a characteristic feature of glyphosate poisoning (Zouaoui et al., 2013). Since glyphosate disrupts sterol sulfation and it disrupts monoamine neurotransmitter synthesis, in addition to its physical kosmotropic feature, it can be anticipated that a chronic exposure to even a small amount of glyphosate over the course of time will lead to a system-wide deficiency in the supply of sulfate to the tissues. We believe that this is the most important consequence of glyphosate's insidious slow erosion of health.

An interesting consideration regarding a known link between celiac disease and hypothyroidism (Collins et al., 2012) emerges when one considers that iodide is one of the few chaotropic (structure breaking) anions available to biological systems: another important one being nitrate, which is elevated in the urine in association with celiac disease (Laurin et al., 2003). It is intriguing that the conversion of T4 to T3 (the active form of thyroid hormone) involves selenium as an essential cofactor. Furthermore, iodide is released in the process, thus providing chaotropic buffering in the blood serum. Therefore, impaired conversion due to deficient selenium results in an inability to buffer this significant chaotrope in the blood, despite the fact that chaotropic buffering is likely desperately needed in the context of the kosmotropic effects of glyphosate. While speculative, it is possible that the autoimmune thyroid disease that develops in association with celiac disease is a direct consequence of the inability to activate thyroid hormone due to insufficient selenium. Indeed, celiac patients with concurrent hypothyroidism require an elevated dose of levothyroxine (T4) compared to nonceliac hypothyroid patients (Collins et al., 2012), which could be due to impaired activation to T3.

The link between autoimmune (type 1) diabetes and autoimmune thyroiditis is likely tied to deficiencies in selenoproteins leading to apoptosis. Diabetic rats produce significantly less glomerular heparan sulfate in the kidneys than controls, and this is associated with increased albuminurea (Jaya et al., 1993). However, children with type-1 diabetes and celiac disease excrete lower levels of albumin than type-1 diabetic children without celiac disease, suggesting a protective role for celiac disease (Gopee et al., 2013). Wheat is a good source of tryptophan, so it is likely that tryptophan-derived serotonin induces the symptoms of diarrhea and nausea associated with wheat ingestion, but, at the same time, transports available sulfate through the vasculature, to help maintain adequate supplies of heparan sulfate to the glomerulus. Thus, the increased metabolism of dietary tryptophan to serotonin observed in association with celiac disease may help ameliorate the sulfate deficiency problem. Glyphosate's interference with CYP enzymes links to impaired bile-acid production in the liver, which in turn impairs sterol-based sulfate transport, placing a higher burden on serotonin for this task.

We have argued here that kidney failure, a known risk factor in celiac disease, is a consequence of depleted sulfate supplies to the kidneys. An alarming increase in kidney failure in young male agricultural workers in sugar cane fields in South America can be directly linked to the recent increase in the practice of using Roundup to "ripen" the crop just prior to the harvest. Furthermore, glyphosate's interference with selenoprotein supply would lead to thyroid dysfunction, which greatly increases risk to kidney disease. We propose here that glyphosate is the key environmental factor contributing to this epidemic, but further investigation is warranted.

While we have covered a broad range of pathologies related to celiac disease in this paper, and have shown how they can be explained by glyphosate exposure, there are likely still other aspects of the disease and the connection to glyphosate that we have omitted. For example, in a remarkable case study (Barbosa, 2001), a 54-year-old man who accidentally sprayed himself with glyphosate developed skin lesions six hours later. More significantly, one month later he exhibited symptoms of Parkinson's disease. Movement disorders such as Parkinsonism are associated with gluten intolerance (Baizabal-Carvallo, 2012). Figure 6 shows plots of glyphosate application to corn and soy alongside plots of deaths due to Parkinson's disease. These and other connections will be further explored in future research.

\section{Conclusion}

Celiac disease is a complex and multifactorial condition associated with gluten intolerance and a higher risk to thyroid disease, cancer and kidney disease, and there is also 


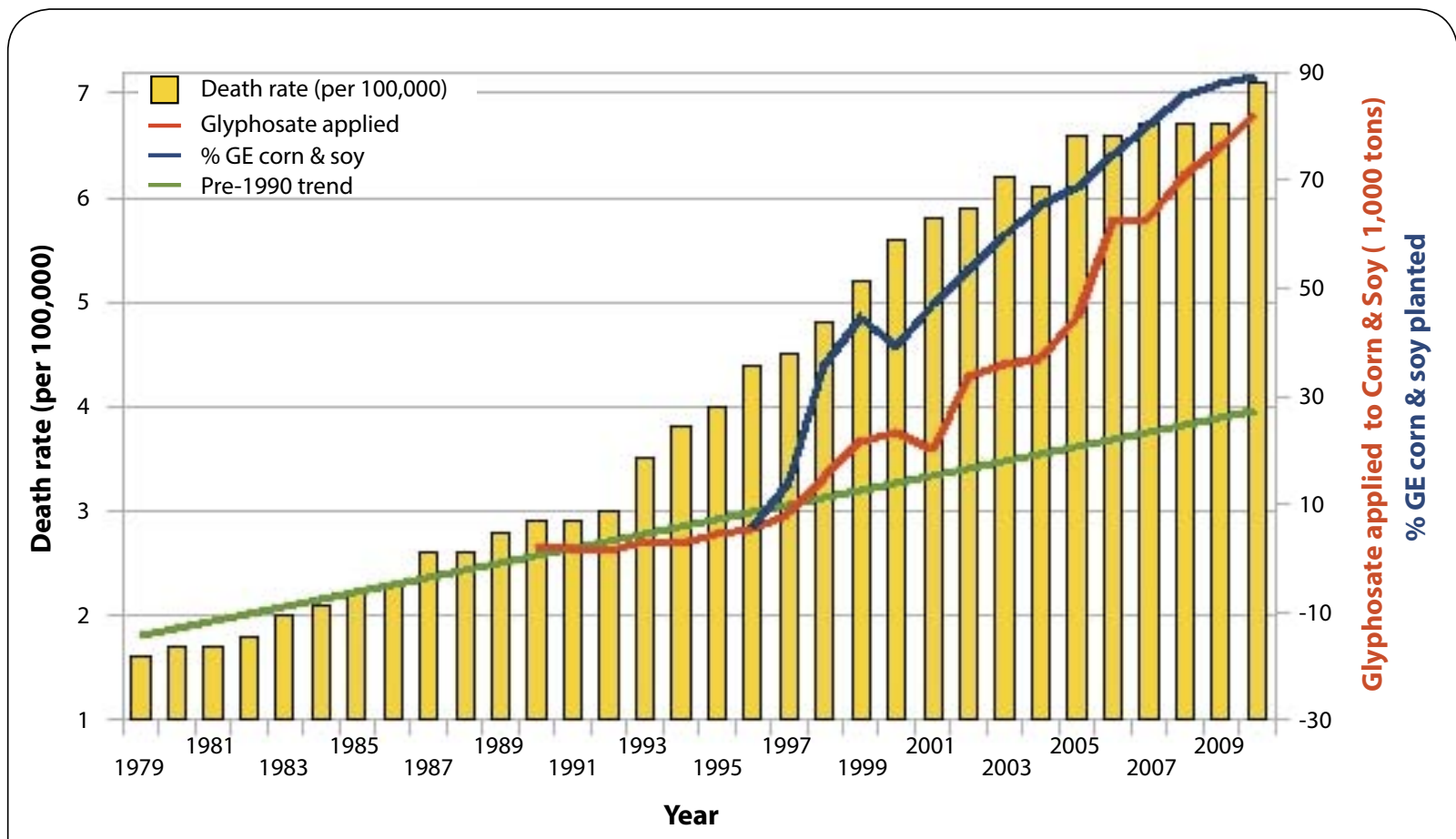

Figure 6. Deaths from Parkinson's disease (ICD G20 \& 332.0) plotted against glyphosate use on corn \& soy (R=0.9006, $p \leq 5.063 e-07)$ and $\% G E$ corn $\&$ soy planted $(\mathrm{R}=0.9676, p \leq 2.714 \mathrm{e}-06)$. Sources: USDA:NASS; CDC. (Figure courtesy of Nancy Swanson).

an increased risk to infertility and birth defects in children born to celiac mothers. While the principal diagnostic is autoantibodies to tissue transglutaminase, celiac disease is associated with a spectrum of other pathologies such as deficiencies in iron, vitamin D3, molybdenum, selenium, and cobalamin, an overgrowth of pathogens in the gut at the expense of beneficial biota, impaired serotonin signaling, and increased synthesis of toxic metabolites like p-Cresol and indole-3-acetic acid. In this paper, we have systematically shown how all of these features of celiac disease can be explained by glyphosate's known properties. These include (1) disrupting the shikimate pathway, (2) altering the balance between pathogens and beneficial biota in the gut, (3) chelating transition metals, as well as sulfur and selenium, and (4) inhibiting cytochrome P450 enzymes. We argue that a key system-wide pathology in celiac disease is impaired sulfate supply to the tissues, and that this is also a key component of glyphosate's toxicity to humans.

The monitoring of glyphosate levels in food and in human urine and blood has been inadequate. The common practice of desiccation and/or ripening with glyphosate right before the harvest ensures that glyphosate residues are present in our food supply. It is plausible that the recent sharp increase of kidney failure in agricultural workers is tied to glyphosate exposure. We urge governments globally to reexamine their policy towards glyphosate and to introduce new legislation that would restrict its usage.

\section{Acknowledgements}

The authors would like to thank Nancy Swanson for her gracious effort in the creation of the informative pictorial graphs included with the text. Her statistical research for glyphosate usage and disease over time is an invaluable contribution to our paper. Stephanie Seneff would also like to personally thank Jennifer Moeny for her most informative discussions concerning current associative prognosis, research and trends in Celiac disease and gluten intolerance. This work was funded in part by Quanta Computers, Taipei, Taiwan, under the auspices of the Qmulus Project.

Disclosures: The authors have nothing to disclose.

\section{REFERENCES}

Agúndez JA, García-Martín E, Martínez C. (2009). Genetically based impairment in CYP2C8- and CYP2C9-dependent NSAID metabolism as a risk factor for gastrointestinal bleeding: Is a combination of pharmacogenomics and metabolomics required to improve personalized medicine? Expert Opin Drug Metab Toxicol 5(6): 607-620.

Ali A. and Fletcher R. A. (1977), Phytotoxic action of glyphosate and amitrole on corn seedlings. Can J Bot 56: 2196-2202.

Allen RH, Stabler SP, Savage DG, and Lindenbaum J. Metabolic abnormalities in cobalamin (vitamin B12) and folate deficiency. (1993) FASEB J 7: 13441353.

Ames BN, Shigenaga MK, Hagen TM. (1993). Oxidants, antioxidants, and the degenerative diseases of aging. Proc Natl Acad Sci U S A 90: 7915-22. 
Baizabal-Carvallo JF, Jankovic J. (2012). Movement disorders in autoimmune diseases. Mov Disord 27(8): 935-46.

Banoglu E, King RS. (2002). Sulfation of indoxyl by human and rat aryl (phenol) sulfotransferases to form indoxyl sulfate. Eur J Drug Metab Pharmacokinet 27(2): 135-140.

Barbosa ER, Leiros da Costa MD, Bacheschi LA, Scaff M, Leite CC. (2001). Parkinsonism after glycine-derivate exposure. Mov Disord 16(3): 565-8.

Bash LD, Erlinger TP, Coresh J, Marsh-Manzi J, Folsom AR, Astor BC. (2009). Inflammation, hemostasis, and the risk of kidney function decline in the Atherosclerosis Risk in Communities (ARIC) Study. Am J Kidney Dis 53: 596605.

Bellaloui N, Reddy KN, Zablotowicz RM, Abbas HK, Abel CA. (2009). Effects of glyphosate application on seed iron and root ferric (III) reductase in soybean cultivars. J Agric Food Chem 57(20): 9569-74.

Benini F, Mora A, Turini D, Bertolazzi S, Lanzarotto F, Ricci C, Villanacci V, Barbara G, Stanghellini V, Lanzini A. (2012). Slow gallbladder emptying reverts to normal but small intestinal transit of a physiological meal remains slow in celiac patients during gluten-free diet. Neurogastroenterol Motil 24(2): 100-7, e79-80.

Benítez-Leite S, Macchi ML, Acosta M (2009). Malformaciones congenítas asociadas a agrotóxicos. Archivos de Pediatría del Uruguay 80: 237-247.

Bergamaschi G, Markopoulos K, Albertini R, Di Sabatino A, Biagi F, Ciccocioppo R, Arbustini E, Corazza GR. (2008). Anemia of chronic disease and defective erythropoietin production in patients with celiac disease. Haematologica 93(12): 1785-91.

Bernfield M, Götte M, Park P-W, Reizes O, Fitzgerald ML, Lincecum J, Zako M. (1999). Functions of cell surface heparan sulfate proteoglycans. Annu Rev Biochem 68: 729-777.

Beswick E, Millo J. (2011). Fatal poisoning with glyphosate-surfactant herbicide. JICS 12(1): 37-39.

Beuret CJ, Zirulnik F, Gimenez MS (2005) Effect of the herbicide glyphosate on liver lipoperoxidation in pregnant rats and their fetuses. Reprod Toxicol 19: 501-504.

Bhatia M. (2012). Role of hydrogen sulfide in the pathology of inflammation. 2012: Article ID 159680.

Björnstedt M, \& Aristi P. Fernandes AP. (2010). Selenium in the prevention of human cancers. EPMA Journal 1: 389-395.

Blanchard C, Rothenberg ME. (2008). Basics pathogenesis of eosinophilic esophagitis. Gastrointest Endosc Clin N Am 18(1): 133-143.

Bode R, Melo C, Birnbaum D. (1984). Mode of action of glyphosate in Candida maltosa. Arch Microbiol 140(1): 83-5.

Boles RG, Ment LR, Meyn MS, Horwich AL, Kratz LE, Rinaldo P. (1993). Shortterm response to dietary therapy in molybdenum cofactor deficiency. Ann Neuro/ 34(5): 742-4.

Boss GR. (1985). Cobalamin inactivation decreases purine and methionine synthesis in cultured lymphoblasts. J Clin Invest 76: 213-218.

Bostwick HE, Berezin SH, Halata MS, Jacobson R, Medow MS. (2001). Celiac disease presenting with microcephaly. J Pediatr 138(4): 589-92.

Bottaro G, Cataldo F, Rotolo N, Spina M, Corazza GR. (1999). The clinical pattern of subclinical/silent celiac disease: an analysis on 1026 consecutive cases. Am J Gastroentero/ 94: 691-6.

Brown AM, Bradshaw MJ, Richardson R, Wheeler JG, Harvey RF. (1987). Pathogenesis of the impaired gall bladder contraction of coeliac disease. Gut 28(11): 1426-1432.

Cabrera-Chávez F, Islas-Rubio AR, Rouzaud-Sández O, Sotelo-Cruz N, Calderón de la Barcaa AM. (2010). Modification of gluten by methionine binding to prepare wheat bread with reduced reactivity to serum IgA of celiac disease patients. J Cereal Sci 52(2): 310-313

Cakal B, Beyazit Y, Koklu S, Akbal E, Biyikoglu I, Yilmaz G. (2010). Elevated adenosine deaminase levels in celiac disease. J Clin Lab Anal 24(5): 323-326.

Cakmak I, Yazici A, Tutus Y, Ozturk L (2009). Glyphosate reduced seed and leaf concentrations of calcium, manganese, magnesium, and iron in nonglyphosate resistant soybean. Eur J Agron 31(3): 114-119.

Cañal MJ, Tamés RS, Fernández B, (1987). Glyphosate-increased levels of indole-3-acetic acid in yellow nutsedge leaves correlate with gentisic acid levels. Physiol Plantar 71(3): 384-388.

Carman JA, Vlieger HR, Ver Steeg LJ, Sneller VE, Robinson GW, Clinch-Jones CA, Haynes Jl, Edwards JW. (2013). A long-term toxicology study on pigs fed a combined genetically modified (GM) soy and GM maize diet. $J$ Organic Syst 8(1): 38-54.
Carrasco A. (2013). Teratogenesis by glyphosate based herbicides and other pesticides: Relationship with the retinoic acid pathway. In: Breckling B, Verhoeven R. GM-Crop Cultivation Ecological Effects on a Landscape Scale. Theorie in der kologie 17. Frankfurt, Peter Lang.

Cavallaro R, lovino P, Castiglione F, Palumbo A, Marino M, Di Bella S, Sabbatini F, Labanca F, Tortora R, Mazzacca G, Ciacci C. (2004). Prevalence and clinical associations of prolonged prothrombin time in adult untreated coeliac disease. Eur J Gastroenterol Hepatol 16(2): 219-223.

Cerdas M. (2005). Chronic kidney disease in Costa Rica. Kidney Int Suppl 97 31-33.

Challacombe DN, Dawkins PD, Baker P. (1977). Increased tissue concentrations of 5-hydroxy-tryptamine in the duodenal mucosa of patients with coeliac disease. Gut 18: 882-886.

Chang CY, Peng YC, Hung DZ, Hu WH, Yang DY, Lin TJ. (1999). Clinical impact of upper gastrointestinal tract injuries in glyphosate-surfactant oral intoxication. Hum Exp Toxicol 18: 475-78.

Chanoine JP, Neve J, Wu S, Vanderpas J, Bourdoux P. (2001). Selenium decreases thyroglobilin concentrations but does not affect the increased thyroxine-to-triiodothyronine ratio in chidren with congenital hypothyroidism. J Clin Endocrinol Metab 86: 1160-1163.

Chin A, Svejda B, Gustafsson BI, Granlund AB, Sandvik AK, Timberlake A, Sumpio B, Pfragner R, Modlin IM, Kidd M. (2012). The role of mechanical forces and adenosine in the regulation of intestinal enterochromaffin cell serotonin secretion. Am J Physiol Gastrointest Liver Physiol 302: G397-G405.

Clotman F, van Maele-Fabry G, Chu-Wu L, Picard JJ. (1998). Structural and gene expression abnormalities induced by retinoic acid in the forebrain. Reprod Toxicol 12: 169-176.

Coleman NS, Foley S, Dunlop SP, Wheatcroft J, Blackshaw E, Perkins AC, Singh G, Marsden CA, Holmes GK, Spiller RC. (2006) Abnormalities of serotonin metabolism and their relation to symptoms in untreated celiac disease. Clin Gastroenterol Hepatol 4: 874-881.

Collado MC, Calabuig M, Sanz Y. (2007). Differences between the fecal microbiota of coeliac infants and healthy controls. Curr Issues Intest Microbio 8(1): 9-14.

Collin P, Kaukinen K, Valimaki M, Salmi J. (2002). Endocrinological disorders and celiac disease. Endocrine Rev 23(4): 464-483.

Collin P, Vilska S, Heinonen PK, Hällström O, Pikkarainen P. (1996). Infertility and coeliac disease. Gut 39(3): 382-384.

Collins D, Wilcox R, Nathan M, Zubarik R. (2012). Celiac disease and hypothyroidism. Am J Med 125(3): 278-82.

Colombato LO, Parodi H, Cantor D. (1977) Biliary function studies in patients with celiac sprue. Am J Dig Dis 22(2): 96-8.

Coombes JL, Siddiqui KR, Arancibia-Cárcamo CV, Hall J, Sun CM, Belkaid Y, Powrie F.. (2007). A functionally specialized population of mucosal CD103+ DCs induces Foxp3+ regulatory T cells via a TGF-beta and retinoic acid-dependent mechanism. J Exp Med 204(8): 1757-64.

Corrao G, Corazza GR, Bagnardi V, Brusco G, Ciacci C, Cottone M, Sategna Guidetti C, Usai P, Cesari P, Pelli MA, Loperfido S, Volta U, Calabr A, Certo M; Club del Tenue Study Group. (2001). Mortality in patients with coeliac disease and their relatives: A cohort study. Lancet 358: 356-361.

Cottone M, Termini A, Oliva L, Magliocco A, Marrone C, Orlando A, Pinzone F, Di Mitri R, Rosselli M, Rizzo A, Pagliaro L. (1999). Mortality and causes of death in celiac disease in a Mediterranean area. Dig Dis Sci 44: 2538-41.

Coussens LM, Werb Z. (2002). Inflammation and cancer. Nature 420: 860-67.

Culpepper, AS, York, AC, Batts, RB, Jennings KM. (2000). Weed Management in Glufosinate- and Glyphosate-Resistant Soybean (Glycine max). Weed Technology 14(1): 77-88.

Cupp MJ, Tracy TS. (1998). Cytochrome P450: New nomenclature and clinical implications. Am Fam Physician 57(1): 107-16.

Cusiel AL. (2005). The Synthesis and Reactivity of Novel Co(L)(PMG).n+Complexes. University of Canterbury, MS Thesis, April.

Dahele A, Ghosh S. (2001). Vitamin B12 deficiency in untreated celiac disease. Am J Gastroenterol 96(3): 745-50.

D’Ari L, Barker HA. (1985). p-Cresol formation by cell free extracts of Clostridium difficile. Arch Microbiol 143: 311-312.

Darwent AL, Kirkland KJ, Townley-Smith L, Harker KN, Cessna AJ, Lukow OM, Lefkovitch LP. (1994). Effect of preharvest applications of glyphosate on the drying, yield and quality of wheat. Can J Plant Sci 74(2): 221-230. 
de Liz Oliveira Cavalli VL, Cattani D, Heinz Rieg CE, Pierozan P, Zanatta L Benedetti Parisotto E, Wilhelm Filho D, Mena Barreto Silva FR, Pessoa-Pureur $R$, Zamoner A. (2013). Roundup disrupts male reproductive functions by triggering calcium-mediated cell death in rat testis and Sertoli cells. Free Radic Biol Med 29(65C): 335-346.

de María N, Becerril JM, Garca-Plazaola Jl, Hernandez AH, de Felipe MR, Fernández-Pascual M. (1996). New insights on glyphosate mode of action in nodular metabolism: Role of shikimate accumulation. J Agric Food Chem 54: $2621-2628$.

DePaolo RW, Abadie V, Tang F, Fehlner-Peach H, Hall JA, Wang W, Marietta EV, Kasarda DD, Waldmann TA, Murray JA, Semrad C, Kupfer S, Belkaid Guandalini YS, Jabri1 B. (2011). Co-adjuvant effects of retinoic acid and IL-15 induce inflammatory immunity to dietary antigens. Nature 471(7337): 220-224.

Deprez P, Sempoux C, Van Beers BE, Jouret A, Robert A, Rahier J, Geubel A, Pauwels S, Mainguet P. (2002). Persistent decreased plasma cholecystokinin levels in celiac patients under gluten-free diet: respective roles of histological changes and nutrient hydrolysis. Regul Pept 110(1): 55-63.

De Roos AJ, Zahm SH, Cantor KP, Weisemburger DD, Holmes FF, Burmeister LF, Blair A. (2003). Integrative assessment of multiple pesticides as risk factors for non-Hodgkins lymphoma among men. Occup Environ Med 60(9): e11.

Di Cagno R, De Angelis M, De Pasquale I, Ndagijimana M, Vernocchi P, Ricciut P, Gagliardi F, Laghi L, Crecchio C, Guerzoni ME, Gobbetti M, Francavilla R. (2011). Duodenal and faecal microbiota of celiac children: Molecular, phenotype and metabolome characterization. BMC Microbiol 11: 219.

Dickey W, McMillan SA, Callender ME. (1997). High prevalence of celiac sprue among patients with primary biliary cirrhosis. J Clin Gastroenterol 25(1): $328-9$.

Dickey W, Ward M, Whittle CR, Kelly MT, Pentieva K, Horigan G, Patton S, McNulty H. (2008). Homocysteine and related B-vitamin status in coeliac disease: Effects of gluten exclusion and histological recovery. Scand J Gastroentero/ 43: 682688.

Dickey W, Stewart F, Nelson J, McBreen G, McMillan SA, Porter KG. (1996) Screening for coeliac disease as a possible maternal risk factor for neural tube defect. Clin Genet 49(2): 107-8.

Dørum S, Arntzen MØ, Qiao S-W, Holm A, Koehler CJ, Thiede B, Sollid LM, Fleckenstein B. (2010). The preferred substrates for transglutaminase 2 in a complex wheat gluten digest are peptide fragments harboring celiac disease T-cell epitopes. PLoS ONE 5(11): e14056.

Dou L, Bertrand E, Cerini C, Faure V, Sampol J, Vanholder R, Berland Y, Brunet P. (2004). The uremic solutes $p$-cresol and indoxyl sulfate inhibit endothelial proliferation and wound repair. Kidney Int 65: 442-451.

Drexler J. (1958). Effect of indole compounds on vitamin B12 utilization. Blood 13(3): 239-44.

Duke, S.O.; Powles, S.B. (2008). Glyphosate: A once-in-a-century herbicide. Pest Manag Sci 64: 319-325.

Egan LJ, Walsh SV, Stevens FM, Connolly CE, Egan EL, McCarthy CF. (1995). Celiac associated lymphoma: A single institution experience of 30 cases in the combination chemotherapy era. J Clin Gastroenterol 21(2): 123-9.

Ejderhamn J, Samuelson K, Strandvik B. (1992) Serum primary bile acids in the course of celiac disease in children. J Pediatr Gastroenterol Nutr 14(4): 443-9.

Eker S, Ozturk L, Yazici A, Erenoglu B, Romheld V, Cakmak I. (2006). Foliar-applied glyphosate substantially reduced uptake and transport of iron and manganese in sunflower (Helianthus annuus L.) plants. J Agric Food Chem 54(26): 10019-25.

El-Shenawy N. (2009). Oxidative stress responses of rats exposed to Roundup and its active ingredient glyphosate. Environ Toxicol Pharmacol 28(3): 379385.

Ellis JK, Russell RM, Makrauer FL, Schaefer EJ. (1986). Increased risk of vitamin A toxicity in severe hypertriglyceridemia. Ann Intern Med 105: 877-9.

Erspamer V. (1986). Historical introduction: The Italian contribution to the discovery of 5-hydroxytryptamine (enteramine, serotonin). J Hypertens Supp/ 4(1): S3-S5.

Esposito C, Paparo F, Caputo I, Rossi M, Maglio M, Sblattero D, Not T, Porta R, Auricchio S, Marzari R, Troncone R. (2002). Anti-tissue transglutaminase antibodies from coeliac patients inhibit transglutaminase activity both in vitro and in situ. Gut 51(2): 177-181.

Famularo G, De Simone C, Pandey V, Sahu AR, Minisola G (2005). Probiotic lactobacilli: an innovative tool to correct the malabsorption syndrome of vegetarians? Med Hypotheses 65 (6): 11325.
Farthing MJG, Edwards CRW, Rees LH, Dawson AM (1982). Male gonadal function in coeliac disease: 1 . Sexual dysfunction, infertility, and semen quality. Gut 23: 608-614.

Fasano A. (2011). Zonulin and its regulation of intestinal barrier function: The biological door to inflammation, autoimmunity, and cancer. Physiol Rev 91 151-175.

Fasano A, Berti I, Gerarduzzi T, Not T, Colletti RB, et al. (2003). Prevalence of celiac disease in at-risk and not-at-risk groups in the United States a large multicenter study. Arch Intern Med 163: 286-292.

Fasano A, Not T, Wang W, Uzzau S, Berti I, Tommasini A, Goldblum SE. (2000). Zonulin, a newly discovered modulator of intestinal permeability, its expression in coeliac disease. Lancet 358: 1518-1519.

Förstermann U, Münzel T. (2006). Endothelial nitric oxide synthase in vascular disease: From marvel to menace. Circulation 113: 1708-14.

Fountoulakis S, Tsatsoulis A. (2004). On the pathogensis of autoimmune thyroid disease: A unifying hypothesis. Clin Endocrinol 60: 397-409.

Franz JE, Mao MK, Sikorski JA. (1997). Glyphosate: A unique global herbicide. American Chemical Society, Publisher.

Freeman HJ. (2010). Reproductive changes associated with celiac disease. World J Gastroenterol 16(46): 5810-5814.

Fukumoto S, Tatewaki M, Yamada T, Fujimiya M, Mantyh C, Voss M, Eubanks S, Harris M, Pappas TN, Takahashi T. (2003). Short-chain fatty acids stimulate colonic transit via intraluminal 5-HT release in rats. Am J Physiol Regul Integr Comp Physio/ 284: R1269-R1276.

Furukawa S, Usuda K, Abe M, Hayashi S, Ogawa I. (2007). Indole-3-acetic acid induces microencephaly in mouse fetuses. Exp Toxicol Pathol 59(1): 43-52.

Furuta GT, Liacouras CA, Collins MH, Gupta SK, Justinich C, Putnam PE, Bonis $\mathrm{P}$, Hassall $\mathrm{E}$, Straumann A, Rothenberg ME; First International Gastrointestinal Eosinophil Research Symposium (FIGERS) Subcommittees. (2007). Eosinophilic esophagitis in children and adults: A systematic review and consensus recommendations for diagnosis and treatment. Gastroenterology 133: 1342-1363.

Ganson RJ, Jensen RA. (1988). The essential role of cobalt in the inhibition of the cytosolic Isozyme of 3-deoxy-D-arabino-heptulosonate-7-phosphate synthase from Nicotiana silvestris by glyphosate. Arch Biochem Biophys 260(1): 85-73.

Gasnier C, Dumont C, Benachour N, Clair E, Chagnon M-C, Seralini G-E. (2009). Glyphosate-based herbicides are toxic and endocrine disruptors in human cell lines. Toxicology 262: 184-191.

Glass RL. (1984). Metal complex formation by glyphosate. Journal of Agricultural and Food Chemistry 32: 1249-1253.

Gobbetti M, Giuseppe Rizzello C, Di Cagno R, De Angelis M.(2007). Sourdough lactobacilli and celiac disease. Food Microbio/ 24(2): 187-96.

Goldman AS, Van Fossan DD, Baird EE. (1962). Magnesium deficiency in celiac disease. Pediatrics 29(6): 948-952.

Gopee E, van den Oever EL, Cameron F, Thomas MC. (2013). Coeliac disease, gluten-free diet and the development and progression of albuminuria in children with type 1 diabetes. Pediatr Diabetes 14(6): 455-8.

Goubern M, Andriamihaja M, Nubel T, Blachier F, Bouillaud F. (2007). Sulfide, the first inorganic substrate for human cells. FASEB J 21(8): 1699-1706.

Green PHR, Cellier C. (2007). Celiac Disease. N Engl J Med 357: 1731-1743.

Green PH, Fleischauer AT, Bhagat G, Goyal R, Jabri B, Neugut Al. (2003). Risk of malignancy in patients with celiac disease. Am J Med 115(3): 191-5.

Grider JR, Piland BE. (2007). The peristaltic reflex induced by short-chain fatty acids is mediated by sequential release of 5-HT and neuronal CGRP but not BDNF. Am J Physiol Gastrointest Liver Physiol 292: G429-G437.

Grigg AP. (1999). Deep venous thrombosis as the presenting feature in a patient with coeliac disease and homocysteinaemia. Aust N Z J Med 29: 566 567.

Gross S, van Wanrooij RL, Nijeboer P, Gelderman KA, Cillessen SAGM, Meijer GA, Mulder CJ, Bouma G, von Blomberg BME, Bontkes HJ. (2013). Differential IL-13 production by small intestinal leukocytes in active coeliac disease versus refractory coeliac disease. Mediators of Inflammation 2013: Article ID 939047.

Grube A, Donaldson D, Kiely T, Wu L. (2011). Pesticide industry sales and usage: 2006 and 2007 market estimates. U.S. Environmental Protection Agency: Washington, DC, USA.

Haderlie LC, Widholm JM, Slife FW. (1977). Effect of glyphosate on carrot and tobacco cells. Plant Physiol 60: 40-43. 
Hadithi M, Mulder CJJ, Stam F, Azizi J, Crusius JBA, Peña AS, Stehouwer CDA Smulders YM. (2009). Effect of B vitamin supplementation on plasma homocysteine levels in celiac disease. World J Gastroenterol 15(8): 955-960.

Halfdanarson TR, Kumar N, Hogan WJ, Murray JA. (2009). Copper deficiency in celiac disease. J Clin Gastroenterol 43(2): 162-4.

Halfdanarson TR, Litzow MR, Murray JA. (2007). Hematologic manifestations of celiac disease. Blood 109: 412-21.

Hallert C, Grant C, Grehn S, Granno C, Hultén S, Midhagen, G, Ström M, Svensson $\mathrm{H}$. Valdimarsson T. (2002). Evidence of poor vitamin status in celiac patients on a gluten-free diet for 10 years. Alimentary Pharmacology \& Therapeutics 16: 1333-1339.

Hardell L, Eriksson M. (1999). A casecontrol study of non-Hodgkin lymphoma and exposure to pesticides. Cancer 85(6): 1353-1360.

Hernanz, A, Polanco I. (1991). Plasma precursor amino acids of central nervous system monoamines in children with coeliac disease. Gut 32: 14781481.

Herrmann W, Obeid R. (2012). Cobalamin deficiency. Subcell Biochem 56: 301 22.

Hershko C, Patz J. (2008). Ironing out the mechanism of anemia in celiac disease. Haematologica 93(12): 1761-1765.

Hietanen E, Linnainmaa K, Vainio H. (1983). Effects of phenoxyherbicides and glyphosate on the hepatic and intestinal biotransformation activities in the rat. Acta Pharmacol Toxicol (Copenh). 53(2): 103-12.

Hildebrandt TM, Grieshaber MK. (2008). Three enzymatic activities catalyze the oxidation of sulfide to thiosulfate in mammalian and invertebrate mitochondria. FEBS J 275(13): 3352-3361.

Hinks LJ, Inwards KD, Lloyd B, Clayton BE. (1984). Body content of selenium in coeliac disease. Br Med J 288: 1862-1863.

Hoagland, RE, Duke SE. (1982). Biochemical effects of glyphosate. In Biochemical Responses Induced by Herbicides; Moreland, D. E., St. John, J. B., Hess, F. D., Eds.; ACS Symposium Series 181; American Chemical Society: Washington, DC, pp 175-205

Högberg L, Webb C, Fälth-Magnusson K, Forslund T, Magnusson KE, Danielsson L, Ivarsson A, Sandström O, Sundqvist T. (2011). Children with screening-detected coeliac disease show increased levels of nitric oxide products in urine. Acta Paediatr 100(7): 1023-7.

Holick MF. (2005). The Vitamin D Epidemic and its Health Consequences. $J$ Nutr 135(11): 2739S-48S

Homann PE. (1967). Studies on the manganese of the chloroplast. Plant Physiology 42: 997-1007.

Hoppe H-W. (2013). Determination of Glyphosate residues in human urine samples from 18 European countries. Report Glyphosate MLHB-2013-0606. Medical Laboratory Bremen, Haferwende 12, 28357 Bremen, Germany, March.

Huggins DR, Reganold JP. (2008). No till: the quiet revolution. Sci Am 99(1): 70-7.

Iglesias P, Díez JJ. (2009). Thyroid dysfunction and kidney disease. European J Endocrinol 160: 503-515.

Ingenbleek Y, Kimura H. (2013). Nutritional essentiality of sulfur in health and disease. Nutr Rev 71(7): 413-32.

Ito N, Iwamori Y, Hanaoka K, Iwamori M. (1998). Inhibition of pancreatic elastase by sulfated lipids in the intestinal mucosa. J Biochem 123: 107-114.

Iwasaki Y, Asai M, Yoshida M, Nigawara T, Kambayashi M, Nakashima N. (2004). Dehydroepiandrosterone-sulfate inhibits nuclear factor-KBdependent transcription in hepatocytes, possibly through antioxidant effect. J Clin Endocrinol Metab 89(7): 3449- 3454.

Jabri B, Sollid LM. (2009). Tissue-mediated control of immunopathology in coeliac disease. Nat Rev Immuno/ 9(12): 858-870.

Jansson EA, Huang L, Malkey R, Govoni M, Nihlén C, Olsson A, Stensdotter M, Petersson J, Holm L, Weitzberg E, Lundberg JO. (2008). A mammalian functional nitrate reductase that regulates nitrite and nitric oxide homeostasis. Nat Chem Biol 4(7): 411-7.

Jasper R, Locatelli GO, Pilati C, Locatelli C. (2012). Evaluation of biochemical, hematological and oxidative parameters in mice exposed to the herbicide glyphosate- Roundup. Interdiscip Toxicol 5(3): 133-140.

Jaya B, Hu L, Bauman JW, Fu SC, Reddi AS. (1993). Effect of galactose regimen on glomerular heparan sulfate synthesis and albumin excretion in diabetic rats. Res Commun Chem Pathol Pharmacol 80(2): 143-52.
Jetten AM, George MA, Pettit GR, Herald CL, Rearick JI. (1989). Action of phorbol esters, bryostatins, and retinoic acid on cholesterol sulfate synthesis: Relation to the multistep process of differentiation in human epidermal keratinocytes. Journal of Investigative Dermatology 93: 108-115.

Kaplan MM, Ohkubo A, Quaroni EG, Sze-Tu D. (1983). Increased synthesis of rat liver alkaline phosphatase by bile duct ligation. Hepatology 3(3): 36876.

Katz A, Dyck RF, Bear RA. (1979). Celiac disease associated with immune complex glomerulonephritis. Clin Nephrol 11(1): 39-44.

Kelly CP, Pothoulakis C, LaMont JT. (1994). Clostridium difficile colitis. N Engl J Med 330: 257-262.

Kemppainen $T$, Kröger $H$, Janatuinen $E$, Arnala I, Kosma VM, Pikkarainen $P$, Julkunen R, Jurvelin J, Alhava E, Uusitupa M. (1999). Osteoporosis in adult patients with celiac disease. Bone 24(3): 249-255.

Kiely T, Donaldson D, Grube A. (2004). Pesticides industry sales and usage 2000 and 2001 market estimates. U.S. Environmental Protection Agency; Washington DC, USA. Ref Type: Report.

Kim M, Cooke HJ, Javed NH, Carey HV, Christofi F, Raybould HE. (2001). D-glucose releases 5-hydroxytryptamine from human BON cells as a model of enterochromaffin cells. Gastroenterology 121: 1400-1406.

Kimmel GL, Kimmel CA, Williams AL, DeSesso JM. (2013). Evaluation of developmental toxicity studies of glyphosate with attention to cardiovascular development. Crit Rev Toxicol 43(2): 79-95.

Kimura $\mathrm{H}$ (2011). Hydrogen sulfide: its production and functions. Experimental Physiology 96: 833-835.

Kitchen LM, Witt WW, Rieck CE. (1981). Inhibition of chlorophyll accumulation by glyphosate. Weed Science 29: 513-516.

Klein NJ, Shennan Gl, Heyderman RS, Levin M. (1992). Alteration in glycosaminoglycan metabolism and surface charge on humanumbilical vein endothelial cells induced by cytokines, endotoxin and neutrophils. J Cell Sci 102: 821-32.

Köhrle J. (2013). Selenium and the thyroid. Curr Opin Endocrinol Diabetes Obes 20(5): 441-8.

Koning F. (2005). Celiac disease: caught between a rock and a hard place. Gastroenterology 129(4): 1294-1301.

Koyama, T, Melzter HY. (1986). A biochemical and neuroendocrine study of the serotonergic system in depression. In: Hippius H, Klerman GL, Matussek N, Eds. New results in depression research. New York: Springer-Verlag, 1986: 164-88.

Krasinski SD, Cohn JS, Schaefer EJ, Russell RM. (1990). Postprandial plasma retinyl ester response is greater in older subjects compared with younger subjects. J Clin Invest 85: 883-92.

Krüger M, Schrödl W, Neuhaus J, Shehata AA. (2013a). Field investigations of glyphosate in urine of Danish dairy cows. J Environ Anal Toxicol 3(5): 100186.

Krüger M, Shehata AA, Schrödl W, Rodloff A. (2013b). Glyphosate suppresses the antagonistic effect of Enterococcus spp. on Clostridium botulinum. Anaerobe 20: 74-78.

Lai TS, Hausladen A, Slaughter TF, Eu JP, Stamler JS, Greenberg CS. (2001). Calcium regulates $\mathrm{S}$-nitrosylation, denitrosylation, and activity of tissue transglutaminase. Biochemistry 40(16): 4904-10.

Lamb DC, Kelly DE, Hanley SZ, Mehmood Z, Kelly SL. (1998). Glyphosate is an inhibitor of plant cytochrome P450: Functional expression of Thlaspi arvensae cytochrome P45071B1/reductase fusion protein in Escherichia coli. Biochem Biophys Res Commun 244: 110-114.

Lang CC, Brown RM, Kinirons MT, Deathridge MA, Guengerich FP, Kelleher D, O'Briain DS, Ghishan FK, Wood AJ. (1996). Decreased intestinal CYP3A in celiac disease: Reversal after successful gluten-free diet: a potential source of interindividual variability in first-pass drug metabolism. Clin Pharmacol Ther 59(1): 41-6.

Lapunzina P. (2002). Celiac disease and microcephaly. J Pediatr 140(1): 141142.

Laurin P, Fälth-Magnusson K, Sundqvist T. (2003). Increase in nitric oxide urinary products during gluten challenge in children with coeliac disease. Scand J Gastroenterology 38(1): 55-60.

Lee J-H, Lee J.(2010). Indole as an intercellular signal in microbial communities. FEMS Microbiol Rev 34: 426-444.

Legendre BL, Gravois KA, Bischoff KP, Griffin JL. (2005). Timing of glyphosate applications, alternatives to the use of glyphosate and response of new varieties to glyphosate in maximizing the yield of sugar per acre of Louisiana sugarcane in 2005. LSU AgCenter Sugarcane Ann Rep 182-191. 
Lerner A, Shapira Y, Agmon-Levin N, Pacht A, Ben-Ami Shor D, López HM Sanchez-Castanon M, Shoenfeld Y. (2012). The clinical significance of 250H-vitamin D status in celiac disease. Clin Rev Allergy Immunol 42(3): 322-30.

Leslie C, Mews C, Charles A, Ravikumara M. (2010). Celiac disease and eosinophilic esophagitis: a true association. J Pediatr Gastroenterol Nutr 50(4): 397-9.

Li H, Liu X, Cui H, Chen Y-R, Cardounel AJ, Zweier JL. (2006). Characterization of the mechanism of cytochrome P450 reductase-cytochrome P450-mediated nitric oxide and nitrosothiol generation from organic nitrates. $J B C$ 281(18): 12546-12554.

Li L, Rose P, Moore PK. (2011). Hydrogen sulfide and cell signaling. Annu Rev Pharmacol Toxicol 51: 169-87.

Liacouras CA, Furuta GT, Hirano I, Atkins D, Attwood SE, Bonis PA, Burks AW Chehade M, Collins MH, Dellon ES, Dohil R, Falk GW, Gonsalves N, Gupta SK, Katzka DA, Lucendo AJ, Markowitz JE, Noel RJ, Odze RD, Putnam PE, Richter JE, Romero Y, Ruchelli E, Sampson HA, Schoepfer A, Shaheen NJ, Sicherer SH, Spechler S, Spergel JM, Straumann A, Wershil BK, Rothenberg ME, Aceves SS. (2011). Eosinophilic esophagitis: Updated consensus recommendations for children and adults. J Allergy Clin Immunol 128: 3-20.

Lindfors K, Blomqvist T, Juuti-Uusitalo K, Stenman S, Venalainen J, Maki M, Kaukinen K. (2008). Live probiotic Bifidobacterium lactis bacteria inhibit the toxic effects induced by wheat gliadin in epithelial cell culture. Clin Exp Immunol 152(3): 552-558.

Lindros KO. (1997). Zonation of cytochrome P450 expression, drug metabolism and toxicity in liver. Gen Pharmacol 28(2): 191-196.

Logan RF, Rifkind EA, Turner ID. (1989). Ferguson A. Mortality in celiac disease. Gastroenterology 97: 265-271.

Lorand L, Graham RM. (2003). Transglutaminases: Crosslinking enzymes with pleiotropic functions. Nat Rev Mol Cell Biol 4: 140-156.

Lorbek G, Lewinska M, Rozman D. (2012). Cytochrome P450s in the synthesis of cholesterol and bile acids-from mouse models to human diseases. FEBS J 279(9): 1516-33.

Lu W, Li L, Chen M, Zhou Z, Zhang W, Ping S, Yan Y, Wang J, Lin M. (2013). Genome-wide transcriptional responses of Escherichia coli to glyphosate, a potent in- hibitor of the shikimate pathway enzyme 5-enolpyruvylshikimate-3-phosphate synthase. Mol Biosyst 9: 522-530.

Lucendo AJ, Sánchez-Cazalilla M. (2012). Adult versus pediatric eosinophilic esophagitis: Important differences and similarities for the clinician to understand. Expert Rev Clin Immunol 8(8): 733-45.

Madsen HEL, Christensen HH, Gottlieb-Petersen C. (1978). Stability constants of copper(II), zinc, manganese(II), calcium, and magnesium complexes of $\mathrm{N}$-(phosphonomethyl)glycine (glyphosate). Acta Chem Scand 32: 79-83.

Manocha M, Khan WI. (2012). Serotonin and GI disorders: An update on clinical and experimental studies. Clin Trans/ Gastroentero/ 3: e13.

Marteau P, Cadranel JF, Messing B, Gargot D, Valla D, Rambaud JC. (1994). Association of hepatic vein obstruction and coeliac disease in North African subjects. J Hepatol 20: 650-653.

Martinelli P, Troncone R, Paparo F, Torre P, Trapanese E, Fasano C, Lamberti A Budillon G, Nardone G, Greco L. (2000). Coeliac disease and unfavourable outcome of pregnancy. Gut 46(3): 332-335.

Matheus-Vliezen EME, Van Halteran H, Tylgut GNJ. (1994). Malignant lymphoma in coeliac disease: various manifestations with distinct symptomatology and prognosis? J Intern Med 236(1): 43-9.

Maton PN, Selden AC, Fitzpatrick ML, Chadwick VS. (1985). Defective gallbladder emptying and cholecystokinin release in celiac disease. Reversal by gluten-free diet. Gastroenterology 88(2): 391-6.

McDuffie HH, Pahwa P, McLaughlin JR, Spinelli JJ, Fincham S, Dosman JA, Robson D, Skinnider LF, Choi NW. (2001). Non-Hodgkins lymphoma and specific pesticide exposures in men: Cross-Canada study of pesticides and health. Cancer Epidemiol Biomarkers Prev 10(11): 1155-1163.

Medina M, De Palma G, Ribes-Koninckx C, Calabuig M, Sanz Y. (2008). Bifidobacterium strains suppress in vitro the pro-inflammatory milieu triggered by the large intestinal microbiota of coeliac patients. J Inflamm (Lond) 5: 19.

Meloni GF, Dessole S, Vargiu N, Tomasi PA, Musumeci S (1999). The prevalence of coeliac disease in infertility. Hum Reprod 14(11): 2759-2761.

Mishra A, Rothenberg ME. (2003). Intratracheal IL-13 induces eosinophilic esophagitis by an IL-5, eotaxin-1, and STAT6 dependent mechanism. Gastroenterology 125: 1419-1427.
Miteva L, Ivanov S, Alexieva V, Karanov E. (2003). Effect of herbicide glyphosate on glutathione levels, glutathione-S-transferase and glutathione reductase activities in two plant species. Comptes Rendus de l'Academie Bulgare des Sciences 56: 79-84.

Módis K, Coletta C, Erdélyi K, Papapetropoulos A, Szabo C. (2013). Intramitochondrial hydrogen sulfide production by 3-mercaptopyruvate sulfurtransferase maintains mitochondrial electron flow and supports cellular bioenergetics. FASEB J 27(2): 601-11.

Monsanto International Sàrl. (2010). The agronomic benefits of glyphosate in Europe. Review of the benefits of glyphosate per market use. Monsanto Europe SA. www.monsanto.com/products/Documents/glyphosate-background-materials/Agronomic\%20 benefits $\% 20$ of $\% 20$ glyphosate $\% 20$ in\%20Europe.pdf [Last accessed Sep. 4, 2013].

Monsanto Technology LLC, Missouri. (2010). Glyphosate formulations and their use for the inhibition of 5-enolpyruvylshikimate-3-phosphate synthase. US Patent number 7771736 B2. https: //www.google.com/patents/ US7771736. [Last accessed Sep. 1, 2013]

Motekaitis RJ, Martell AE. (1985). Metal chelate formation by N-phosphonomethylglycine and related ligands. J Coord Chem 14: 139-149.

Mora JR, Iwata M, von Andrian UH. (2008). Vitamin effects on the immune system: Vitamins A and D take centre stage. Nat Rev Immuno/ 8(9): 685-98.

Mucida D, Park Y, Kim G, Turovskaya O, Scott I, Kronenberg M, Cheroutre H. (2007). Reciprocal TH17 and regulatory T cell differentiation mediated by retinoic acid. Science 317(5835): 256-260

Murch SH. (1995). Sulphation of proteoglycans and intestinal function. J Gastroenterol Hepatol 10: 210-12.

Murch SH, MacDonald TT, Walker-Smith JA, Levin M, Lionetti P, Klein NJ. (1993). Disruption of sulphated glycosaminoglycans in intestinal inflammation. Lancet 341: 711-14.

Murch SH, Winyard PJ, Koletzko S, Wehner B, Cheema HA, Risdon RA, Phillips AD, Meadows N, Klein NJ, Walker-Smith JA. (1996). Congenital enterocyte heparan sulphate deficiency with massive albumin loss, secretory diarrhoea, and malnutrition. Lancet 347(9011): 1299-301.

Nadal I, Donat E, Ribes-Koninckx C, Calabuig M, Sanz Y. (2007). Imbalance in the composition of the duodenal microbiota of children with coeliac disease. J Med Microbio/ 56: 1669-74.

Nafziger ED, Widholm JM, Steinrücken HC, Killmer JL. (1984). Selection and characterization of a carrot cell line tolerant to glyphosate. Plant Physiol 76(3): 571-4.

Nalewaja JD, Matysiak R. (1993). Influence of diammonium sulfate and other salts on glyphosate phytotoxicity. Pesticide Science 38: 77-84.

Nanda S. (2011). Celiac disease: Retinoic acid and IL-15 jointly implicated in reversal of oral tolerance. Nat Rev Gastroenterol Hepatol 8: 181.

Negri E. (2010). Sun exposure, vitamin D, and risk of Hodgkin and non-Hodgkin lymphoma. Nutr Cancer 62(7): 878-82.

Nelson MA, Porterfield BW, Jacobs ET, Clark LC. (1999). Selenium and prostate cancer prevention. Semin Urol Oncol 17(2): 91-6.

Network Coordinating Council. (May, 2013). 2012 Annual Report. End Stage Renal Disease Network 13. http: //www.network13.org/PDFs/NW13 Annual Report 2012 Final.pdf [Last accessed Sept 3, 2013]

Nielsen $\mathrm{OH}$, Jacobsen O, Pedersen ER, Rasmussen SN, Petri M, Laulund S, Jarnum S. (1985). Non-tropical sprue. Malignant diseases and mortality rate. Scand J Gastroenterol 20: 13-18.

Niwa T. (2010). Indoxyl sulfate is a nephro-vascular toxin. J Ren Nutr 20(5 Suppl): S2-6.

Nomura NS, Hilton HW. (1977). The adsorption and degradation of glyphosate in five Hawaiian sugarcane soils. Weed Res 17: 113-121.

O'Keeffe MG. (1980). The control of Agropyron repens and broad-leaved weeds pre-harvest of wheat and barley with the isopropylamine salt of glyphosate. Proceedings of British Crop Protection Conference - Weeds, 53-60.

O'Keeffe MG.(1981). The control of perennial grasses by pre-harvest applications of glyphosate. Proceedings of the Conference on Grass Weeds in Cereals in the United Kingdom. Association of Applied Biologists, Warwick, UK, 137144.

Orgeron AJ. (2012). Sugarcane growth, sucrose content, and yield response to the ripeners glyphosate and trinexapacethyl. PhD Dissertation, School of Plant, Environmental, and Soil Sciences, Louisiana State University.

Orson JH, Davies DKH. (2007). Pre-harvest glyphosate for weed control and as a harvest aid in cereals. Research Review No. 65. HGCA. 
Paganelli A, Gnazzo V, Acosta H, López SL, Carrasco AE. (2010). Glyphosatebased herbicides produce teratogenic effects on vertebrates by impairing retinoic acid Signaling. Chem Res Toxicol 23: 1586-1595.

Papp LV, Lu J, Holmgren A, Khanna KK. (2007). From selenium to selenoproteins: Synthesis, identity, and their role in human health. Antiox Redox Signal 9: 775-806.

Patel RS, Johlin FC Jr, Murray JA. (1999). Celiac disease and recurrent pancreatitis. Gastrointest Endosc 50(6): 823-827.

Pavkov KL, Turnier JC. (1986). 2-Year chronic toxicity and oncogenicity dietary study with SCm-0224 in mice. T-11813. Farmington: Stauffer Chemical Company.

Peixoto F. (2005). Comparative effects of the Roundup and glyphosate on mitochondrial oxidative phosphorylation. Chemosphere 61(8): 1115-1122.

Peraza S, Wesseling C, Aragon A, Leiva R, Garca-Trabanino RA, Torres C, Jakobsson K, Elinder C, Hogstedt C. (2012). Decreased kidney function among agriculture workers in El Salvador. Am J Kidney Dis 59: 531-540.

Pessione E. (2012). Lactic acid bacteria contribution to gut microbiota complexity: Lights and shadows. Front Cell Infect Microbio/ 2: 86

Peters U, Askling J, Gridley G, Ekbom A, Linet M. (2003). Causes of death in patients with celiac disease in a population-based Swedish cohort. Arch Intern Med 163(13): 1566-1572.

Ponchon G, Kennan AL, DeLuca HF. (1969). Activation of vitamin D by the liver. J Clin Invest 48(11): 2032-2037.

Prabhakar R, Morokuma K, Musaev DG. (2006). Peroxynitrite reductase activity of selenoprotein glutathione peroxidase: A computational study. Biochemistry 45: 6967-6977.

Prasad GA, Alexander JA, Schleck CD, Zinsmeister AR, Smyrk TC, Elias RM Locke GR 3rd, Talley NJ. (2009). Epidemiology of eosinophilic esophagitis over three decades in Olmsted County, Minnesota. Clin Gastroenterol Hepatol 7: 1055-1061.

Pricolo VE, Mangi AA, Aswad B, Bland KI. (1998). Gastrointestinal malignancies in patients with celiac sprue. Am J Surg 176: 344-7.

Putcha GV, Le S, Frank S, Besirli CG, Clark K, Chu B, Alix S, Youle RJ, LaMarche A, Maroney AC, Johnson EM Jr. (2003). JNK-mediated BIM phosphorylation potentiates BAX-dependent apoptosis. Neuron 38(6): 899-914.

Qiao S-W, Bergseng E, Molberg, $\varnothing$, Jung G, Fleckenstein B, Solli LM. (2005). Refining the Rules of Gliadin T Cell Epitope Binding to the Disease-Associated DQ2 Molecule in Celiac Disease: Importance of Proline Spacing and Glutamine Deamidation. J Immuno/ 175(1): 254-261.

Ramirez-Rubio O, Brooks DR, Amador JJ, Kaufman JS, Weiner DE, Scammell MK. (2013). Chronic kidney disease in Nicaragua: A qualitative analysis of semi-structured interviews with physicians and pharmacists. MC Public Health 13: 350.

Refsum H, Yajnik CS, Gadkari M, Schneede J, Vollset SE, Orning L, Guttormsen AB, Joglekar A, Sayyad MG, Ulvik A, Ueland PM. (2001). Hyperhomocysteinemia and elevated methylmalonic acid indicate a high prevalence of cobalamin deficiency in Asian Indians. Am J Clin Nutr 74: 233-41.

Relyea RA. (2005). The lethal impact of Roundup on aquatic and terrestria amphibians. Ecol App/ 15: 1118-1124.

Richard EP Jr, Dalley CD. (2009). Effects of glyphosate ripener timing and rate on cane and sugar yields. J Am Soc Sug Cane Techno/ 29: 81-82.

Rivabene R, Mancini E, Vincenzi M. (1999). In vitro cytotoxic eject of wheat gliadin-derived peptides on the Caco-2 intestinal cell line is associated with intracellular oxidative imbalance: implications for coeliac disease. Biochi Biophys Acta 1453: 152-160.

Rodríguez-Iturbe B, Garca Garca G. (2010). The role of tubulointerstitial inflammation in the progression of chronic renal failure. Nephron Clin Pract 116: $\mathrm{c} 81-\mathrm{c} 88$

Roe DA. (1971). Effects of methionine and inorganic sulfate on indole toxicity and indican excretion in rats. J Nutr 101(5): 645-53.

Rossi M, Amaretti A, Raimondi S. (2011). Folate production by probiotic bacteria. Nutrients 3(1): 118-34

Rubio-Tapia A, Kyle RA, Kaplan EL, Johnson DR, Page W, Erdtmann F, Brantner TL, Kim WR, Phelps TK, Lahr BD, Zinsmeister AR, Melton LJ 3rd, Murray JA. (2009). Increased prevalence and mortality in undiagnosed celiac disease. Gastroenterology 137(1): 88-93.

Rude RK, Olerich M. (1996). Magnesium deficiency: possible role in osteoporosis associated with gluten-sensitive enteropathy. Osteoporos Int 6(6): 453-61.
Russell RM. (2000). The vitamin A spectrum: From deficiency to toxicity. Am J Clin Nutr 71: 878-84.

Saad RJ, Chey WD. (2006). Review article: Current and emerging therapies for functional dyspepsia. Aliment Pharmacol Ther 24(3): 475-492.

Saes Zobiole LH, de Oliveira RS Jr, Kremer RJ, Muniz AS, de Oliveira, A Jr. (2010). Nutrient accumulation and photosynthesis in glyphosate-resistant soybeans is reduced under glyphosate use. J Plant Nutr 33: 1860-1873.

Saibeni S, Lecchi A, Meucci G, Cattaneo M, Tagliabue L, Rondonotti E, Formenti S, De Franchis R, Vecchi M. (2005). Prevalence of hyperhomocysteinemia in adult gluten-sensitive enteropathy at diagnosis: Role of B12, folate and genetics. Clin Gastroenterol Hepatol 3: 574-580.

Sakaki T, Kagawa N, Yamamoto K, Inouye K. (2005). Metabolism of vitamin D3 by cytochromes P450. Front Biosci 10: 119-34.

Sammons RD, Gruys KJ, Anderson KS, Johnson KA, Sikorski JA. (1995). Reevaluating glyphosate as a transition-state inhibitor of EPSP synthase: Identification of an EPSP synthase.EPSP.glyphosate ternary complex. Biochemistry 34(19): 6433-40.

Samsel A, Seneff S. (2013). Glyphosate's suppression of cytochrome P450 enzymes and amino acid biosynthesis by the gut microbiome: Pathways to modern diseases. Entropy 15: 1416-1463.

Sanoff SL, Callejas L, Alonso CD, Hu Y, Colindres RE, Chin H, Morgan DR, Hogan SL. (2010). Positive association of renal insufficiency with agriculture employment and unregulated alcohol consumption in Nicaragua. Ren Fail 32: 766-777.

Sanz Y, De Palma G, Laparra M. (2011). Unraveling the ties between celiac disease and intestinal microbiota. International Reviews of Immunology 30(4): 207-218.

Selvapandiyan A, Majumder K, Fattah FA, Ahmad S, Arora N, Bhatnagar RK. (1995). Point mutation of a conserved arginine (104) to lysine introduces hypersensitivity to inhibition by glyphosate in the 5-enolpyruvylshikimate-3-phosphate synthase of Bacillus subtilis. FEBS Lett 374(2): 253-6.

Senapati T, Mukerjee AK, Ghosh AR. (2009). Observations on the effect of glyphosate based herbicide on ultra structure (SEM) and enzymatic activity in different regions of alimentary canal and gill of Channa punctatus (Bloch). Journal of Crop and Weed 5(1): 236-245.

Seneff S, Lauritzen A, Davidson R, Lentz-Marino L. (2012). Is endothelial nitric oxide synthase a moonlighting protein whose day job is cholesterol sulfate synthesis? Implications for cholesterol transport, diabetes and cardiovascular disease. Entropy 14: 2492-2530.

Shapira Y, Agmon-Levina N, Shoenfeld Y. (2010). Defining and analyzing geoepidemiology and human autoimmunity. Journal of Autoimmunity $\mathbf{3 4}$ J168-J177.

Shehata AA, Schrödl W, Aldin AA, Hafez HM, Krüger M. (2013). The effect of glyphosate on potential pathogens and beneficial members of poultry microbiota in vitro. Curr Microbiol 66: 350-358.

Sher L. (2000). Selenium and human health. Lancet 356: 233-241.

Singhal N, Alam S, Sherwani R, Musarrat J. (2008). Serum zinc levels in celiac disease. Indian Pediatr 45(4): 319-21.

Smecuol E, Hwang HJ, Sugai E, Corso L, Cheravsky AC, Bellavite FP, González A, Vodánovich $F$, Moreno ML, Vázquez $H$, Lozano G, Niveloni S, Mazure $R$, Meddings J, Maurio E, Bai JC. (2013). Exploratory, randomized, doubleblind, placebo-controlled study on the effects of Bifidobacterium infantis natren life start strain super strain in active celiac disease. J Clin Gastroenterol 47(2): 139-47.

Soderland P, Lovekar S, Weiner DE, Brooks DR, Kaufman JS. (2010). Chronic kidney disease associated with environmental toxins and exposures. Adv Chronic Kidney Dis 17(3): 254-64.

Sonnenberg A, McCarty DJ, Jacobsen SJ. (1991). Geographic variation of inflammatory bowel disease within the United States. Gastroenterology 100: $143 e 9$.

State-Specific Trends in Chronic Kidney Failure —United States, 1990-2001. http: //www.cdc.gov/mmwr/preview/mmwrhtml/mm5339a3.htm. [Last accessed Sept. 3, 2013]

Stride CD, Edwards RV and Seddon JC. (1985). Sward destruction by applica tion of glyphosate before cutting or grazing. British Crop Protection Conference - Weeds 7B-6, 771-778.

Subiros JF. (1990). The effect of applying glyphosate as ripener in three varieties. Turrialba 40(4): 527-534.

Sulik KK, Cook CS, Webster WS. (1988) Teratogens and craniofacial malformations: relationships to cell death. Development 103 Suppl: 213-231. 
Sun $\mathrm{C}-\mathrm{Y}$, Hsu H-H, Wu M-S. (2012). p-Cresol sulfate and indoxyl sulfate induce similar cellular inflammatory gene expressions in cultured proximal renal tubular cells. Nephrol Dial Transplant 28(1): 70-8.

Sunergren KP, Fairman RP, deBlois GG, Glauser FL. (1987). Effects of protamine, heparinase and hyaluronidase on endothelial permeability and surface charge. J Appl Physiol 63: 1987-92.

Taimi M, Helvig C, Wisniewski J, Ramshaw H, White J, Amad M, Korczak B, Petkovich M. (2004). A novel human cytochrome P450, CYP26C1, involved in metabolism of 9-cis and all-trans isomers of retinoic acid. J Biol Chem 279: 77-85.

Tamm AO. (1984). Biochemical activity of intestinal microflora in adult coeliac disease. Nahrung 28(6-7): 711-5.

Thacher SM, Coe EL, Rice RH. (1985). Retinoid suppression of transglutaminase activity and envelope competence in cultured human epidermal carcinoma cells: Hydrocortisone is a potent antagonist of retinyl acetate but not retinoic acid. Differentiation 29(1): 82-87.

Thompson WW, Weier TE. (1962). The fine structure of chloroplasts from mineral-deficient leaves of Phaseolus vulgaris. Am J Bot 49: 1047-1056.

Tieri P, Termanini A, Bellavista E, Salvioli S, Capri M, Franceschi C. (2012). Charting the NF-KB pathway interactome map. PLoS One 7(3): e32678.

Tonelli M, Sacks F, Pfeffer M, Jhangri GS, Curhan G; Cholesterol and Recurrent Events (CARE) Trial Investigators. (2005). Biomarkers of inflammation and progression of chronic kidney disease. Kidney Int 68: 237-245.

Torres C, Aragon A, Gonzalez M, Lopez I, Jakobsson K, Elinder CG, Lundberg I, Wesseling C. (2010). Decreased kidney function of unknown cause in Nicaragua: a community-based survey. Am J Kidney Dis 55: 485-496.

Trabanino RG, Aguilar R, Silva CR, Mercado MO, Merino RL. (2002). End-stage renal disease among patients in a referral hospital in El Salvador. Rev Panam Salud Publica 12: 202-206. [article in Spanish]

Triggiani V, Tafaro E, Giagulli VA, Sabbà C, Resta F, Licchelli B, Guastamacchia E. (2009). Role of iodine, selenium and other micronutrients in thyroid function and disorders. Endocr Metab Immune Disord Drug Targets 9(3): 277-94.

Turnbull J, Powell A, Guimond S. (2001). Heparan sulfate: Decoding a dynamic multifunctional cell regulator. Trends Cell Biol 11: 75-82.

Tursi A, Brandimarte G, Giorgetti G. (2003). High prevalence of small intestinal bacterial overgrowth in celiac patients with persistence of gastrointestinal symptoms after gluten withdrawal. Am J Gastroenterol 98: 839843.

Uggla C, Moritz T, Sandberg G, Sundberg B. (1996). Auxin as a positional signal in pattern formation in plants. Proc Natl Acad Sci U S A 93(17): 9282-86.

Undabeytia TS, Morillo E, Maqueda C. (2002). FTIR study of glyphosate-copper complexes. J Agric Food Chem 50: 1918-1921.
Valentino R, Savastano S, Maglio M, Paparo F, Ferrara F, Dorato M, Lombardi G, Troncone R. (2002). Markers of potential coeliac disease in patients with Hashimoto's thyroiditis. Eur JEndocrinol 146: 479-483.

Vencill WK (ed) (2002). Herbicide handbook. 8th ed. Weed Science Society of America, Lawrence, KS. USA.

Vernier RL, Klein DJ, Sisson SP, Mahan JD, Oegema TR, Brown DM. (1983). Heparan sulphate-rich anionic sites in the human glomerular basement membrane: decreased concentration in congential nephrotic syndrome. $N$ Engl J Med 309: 1001-9.

Vigfusson NV, Vyse ER. (1980).The effect of the pesticides, Dexon, Captan and Roundup, on sister-chromatid exchanges in human lymphocytes in vitro. Mutat Res 79: 53-7.

Waltz E. (2010). Glyphosate resistance threatens Roundup hegemony. Nat Biotechnol 28: 537-538.

Welander A, Prütz KG, Fored M, Ludvigsson JF. (2012). Increased risk of end stage renal disease in individuals with coeliac disease. Gut 61(1): 64-8.

Wheeler EE, Challacombe DN. (1984). Quantification of enterochromaffin cells with serotonin immunoreactivity in the duodenal mucosa in coeliac disease. Arch Dis Child 59: 523-527.

Whorwell PJ, Altringer L, Morel J, Bond Y, Charbonneau D, O'Mahony L, Kiely B, Shanahan F, Quigley EM. (2006). Efficacy of an encapsulated probiotic Bifidobacterium infantis 35624 in women with irritable bowel syndrome. Am J Gastroenterol 101(7): 1581-90.

Wikvall K. (2001). Cytochrome P450 enzymes in the bioactivation of vitamin $\mathrm{D}$ to its hormonal form (review). Int J Mol Med 7(2): 201-9.

Williams GM, Kroes R, Munro IC. (2000). Safety evaluation and risk assessment of the herbicide Roundup and its active ingredient, glyphosate, for humans. Regul Toxicol Pharmacol 31(2 Pt 1): 117-165.

Zaflarska-Popławska A, Siomek A, Czerwionka-Szaflarska M, Gackowski D Rozalski R, Guz J, Szpila A, Zarakowska E, Olinski R. (2010). Oxidatively damaged DNA/oxidative stress in children with celiac disease. Cancer Epidemio Biomarkers Prev 19(8): 1960-1965

Zenjari T, Boruchowicz A, Desreumaux P, Laberenne E, Cortot A, Colombel JF. (1995). Association of coeliac disease and portal venousthrombosis. Gas troenterol Clin Biol. 19: 953-954.

Zhao F-J, Lopez-Bellido FJ, Gray CW, Whalley WR, Clark LJ, McGrath SP. (2007) Science of The Total Environment 372(2-3): 433-439.

Ziolkowski AF, Popp SK, Freeman C, Parish CR, Simeonovic CJ. (2012). Heparan sulfate and heparanase play key roles in mouse cell survival and autoimmune diabetes. J Clin Invest 122(1): 132-141.

Zouaoui K, Dulaurent S, Gaulier JM, Moesch C, Lachâtre G. (2013). Determination of glyphosate and AMPA in blood and urine from humans: About 13 cases of acute intoxication. Forensic Sci Int 226(1-3): e20-5. 